\title{
Comparison of experimental and operationalmodal analysis on a back to back planetary gear
}

\author{
Ayoub Mbarek ${ }^{a, b}$, Alfonso Fernández Del Rincon ${ }^{b}$,Ahmed Hammami ${ }^{a}$,Miguel \\ Iglesias $^{\mathbf{b}}$, Fakher Chaaria ${ }^{\text {, Fernando Viadero }}{ }^{\mathrm{b}}$, Mohamed Haddar ${ }^{\mathrm{a}}$ \\ ayoubmbarekenit@gmail.com, alfonso.fernandez@unican.es, \\ ahmed.hammami2109@gmail.com,miguel.iglesias@unican.es,fakher.chaari@gmail.co

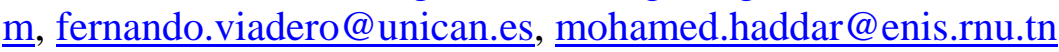 \\ ${ }^{a}$ Mechanics, Modelling and Production Laboratory, National School of Engineers Sfax, \\ BP 1173, 3038 Sfax, Tunisia \\ ${ }^{b}$ Department of Structural and Mechanical Engineering, Faculty of Industrial and \\ Telecommunications Engineering, University of Cantabria, Avda. de los Castros s/n, \\ 39005 Santander, Spain
}

\begin{abstract}
:
Several modal analysis techniques are widely used to study the dynamic characteristics of a structure byidentifying the modal parameters. This paper presented a comparison between anExperimental Modal Analysis (EMA) test and an Operational Modal Analysis (OMA) test and an Order Based Modal Analysis (OBMA) applied on a recirculating energy planetary gear. TheOMA and OBMA offer a test of the planetary gear under its realboundary conditions, whereas the EMA is based on the frequency response function estimation. Using the different techniques, the back to back planetary gearmodal parameterswereidentified. In afirst step, the experimental results determined by EMA and OMA were correlated to the numerical results model obtained by athreedimensional lumped parameter model. In asecond step,the OBMA estimated modal parameters were compared to those of the EMA.

According to the obtained results, OMA cannot excite all the modes. However,it was noticed that there is no significant differencebetween the modal parameters obtained by the EMA and theOBMA.The natural frequencies and damping ratios were deviating by $11 \%$ and $2.43 \%$, respectively.
\end{abstract}

\section{Highlights}

- Planetary gear natural frequencies and damping ratios wereidentified with three different modal analysis techniques.

- FRF, Cross Power Spectral Density, Order Function, Mode shapes,modal assurance criterion and stability diagram were presented.

- Modal analysis under rotating excitation is different from the conventional modal analysis.

- Validation by three-dimensional lumped parameter model.

Keywords Planetary gear, Operational, Orderanalysis, Modalanalysis, Threedimensional model

\begin{tabular}{|ll|}
\hline Nomenclature & \\
$\mathrm{r}$ & Ring \\
$\mathrm{c}$ & Carrier \\
$\mathrm{S}$ & Sun \\
$\mathrm{P} 1$ & Planet 1 \\
\hline
\end{tabular}




\begin{tabular}{|c|c|}
\hline $\mathrm{P} 2$ & Planet 2 \\
\hline P3 & Planet 3 \\
\hline $\mathrm{K}_{r p}$ & The ring-planet mesh stiffness \\
\hline $\mathrm{K}_{s p}$ & The sun-planet mesh stiffness \\
\hline $\mathrm{k}_{\mathrm{cf}}$ & The carrier 's shaft flexural stiffness \\
\hline $\mathrm{k}_{\mathrm{sf}}$ & The sun 's shaft flexural stiffness \\
\hline $\mathrm{k}_{\mathrm{ct}}$ & The carrier 's shaft torsional stiffness \\
\hline Kst & The sun 's shaft torsional stiffness \\
\hline $\mathrm{k}_{\mathrm{ca}}$ & The carrier 's shaft axial stiffness \\
\hline $\mathrm{k}_{\mathrm{sa}}$ & The sun 's shaft axial stiffness \\
\hline$w_{i}$ & Natural pulsations \\
\hline$\varphi_{\mathrm{i}}$ & Vibrations modes \\
\hline q & Degree of freedom vector \\
\hline M & Global mass matrix \\
\hline $\mathrm{K}_{\mathrm{b}}$ & Bearing stiffness matrix \\
\hline $\mathrm{K}_{\mathrm{e}}(\mathrm{t})$ & Time varying mesh stiffness matrix \\
\hline $\mathrm{K}_{\mathrm{c}}$ & Coupled matrix \\
\hline $\mathrm{C}$ & Damping matrix \\
\hline $\mathrm{F}(\mathrm{t})$ & External force \\
\hline$\psi \mathrm{r}$ & Ring-planet pressure angle \\
\hline$\psi_{\mathrm{s}}$ & Sun-planet pressure angle \\
\hline$\alpha_{\mathrm{i}}$ & Planet i angular position \\
\hline$\alpha_{\mathrm{s}}$ & The sun pressure angle \\
\hline$\alpha_{\mathrm{r}}$ & The ring pressure angle \\
\hline $\mathrm{R}_{b r}$ & The rings base radius \\
\hline $\mathrm{R}_{\mathrm{bs}}$ & The suns base radius \\
\hline $\mathrm{R}_{\mathrm{bp}}$ & The planets base radius \\
\hline $\mathrm{m}_{i j}$ & Masses of component $i$ of gear $j$ \\
\hline $\mathrm{I}_{i j}$ & Inertia of component $i$ of gear $j$ \\
\hline $\mathrm{k}_{i j k}$ & Bearing stiffness of component $\mathrm{i}$ of gear $\mathrm{j}$ in $\mathrm{k}$ direction \\
\hline fs & Sampling frequency \\
\hline subscripts & \\
\hline $\mathrm{i}=\mathrm{r}, \mathrm{c}, \mathrm{s}, \mathrm{p} 1, \mathrm{p} 2, \mathrm{p} 3$ & Denotes respectively ring, carrier, sun, planet 1 , planet 2 , planet 3 \\
\hline $\mathrm{j}=\mathrm{r}, \mathrm{t}$ & Denotes respectively reaction gear and test gear \\
\hline $\mathrm{k}=\mathrm{u}, \mathrm{v}, \mathrm{w}, \phi, \Psi, \theta$ & Denotes axis direction \\
\hline
\end{tabular}

\section{Introduction:}

Nowadays, planetary gear transmissions are widely used in different mechanical applications such as cars, wind turbine and a lot ofrotating machinery. These systems are characterized by complex kinematic and dynamic compositions. The diagnosis of these systems could be a very important task for research. Many developmentswereachieved to characterize these systems. The modal properties determination is one of the main investigated issues.

The different available modal analysis kinds are the Experimental Modal Analysis (EMA), Operational Modal Analysis (OMA)and Order Based Modal Analysis(OBMA). EMA techniques are based on impact test, and an excited mechanical structure by means of ahammer or shaker. The frequency response functions are determined, and modes as well as modal dampingare estimated. TheEMAhas three critical drawbacks:firstly, the impact test needs to be repeated to accurately understand the dynamic 
behaviour.Secondly, in many engineeringapplications, and under real operating conditions the obtainedresults may differ significantly from those achieved in lab testing with an artificial excitation.Thirdly, the use of shakercan be an additional load for structures and may lead to erroneous results.

Many researchersimplementedthistechnique to study the dynamic properties of planetary gears. Hammamiet al[1] studied a modal analysis of back to back planetary gear. They validated their experimental results using those issued from thelumped parameters model.Ericson and Parker [2] applied anexperimental modal analysis to characterize the dynamic behaviour of two spur planetary gears. They validated the experimental results by those obtained fromboth of thefinite elements model and lumped parameter model.

Kahraman [3] proposed a simplified rotational lumped-parameter model, providing closed-form expressions for the torsional natural frequencies in terms of system parameters. Zhang et al[4], however, established a translational-rotational coupled dynamic model of a two-stage planetary gear set to anticipate natural frequencies and vibration modes.

Lin and Parker [5] used a two-dimensionalplanetary gear modelwith equal planet spacing to explain the unique modal properties. The compound planetary gears vibration modes were studied by Kiracofe and Parker [6] and Guo and Parker [7].

The second technique is theOMA also known asan output-only modal analysis. It is based on the determination of the modal proprieties under operational tests.It is widely used for the rotating machinery to characterize their modal proprieties. Chauhan et al[8] studied the dynamic characterization of a wind turbine gearbox. They identified its modes shapes through the finite element modeland correlated the numerical modes shapes with those obtained experimentally.Bajrićet al[9] evaluated thedamping of a wind turbine and proposed an automated procedure to determine damping under operating conditions.Gadeet al[10] applied the operational modal analysis to a wind turbine gearbox. They identified natural frequency, modal damping and mode shapesexperimentally.Di Lorenzo et al [11] used the OMA techniques for a wind turbine gearbox, determining the modal parameters in different load conditions experimentally by measuring the accelerations in different locations.

The third technique, known as OBMA is characterized by the scarcity of its experimental studies. It is a relatively new technique based on the extraction of modal proprieties during run up or run-down test, andimplemented by Di Lorenzo et al [12]. The authors developed a finite element model referred to an experimental test rig, and correlated experimental and theoretical results. Randall et al [13] studied the effects of variable speed harmonic orders in an operational modal analysis of a gearbox casing. They proposed two methods to remove variable speed harmonic order. Their achieved results were comparable with those of the hammer excitation. Hammami et al [14]used a torsional model of planetary gear to study the dynamic behaviour in run up and rundown conditions. The natural frequencies are identified from the numerical results obtained by Short Time Fourier Transform and compared to those obtained by the impact test. Janssens et al [15] used this method to determine modal characteristic of an engine. They applied a poly-reference modal parameter estimation called Polymax method to the tracked engine order to identify the resonances. The Polymax modal parameter estimation was developed by B. Peeters et al [16], The method yields very clean stabilization diagrams, easing the problem of selecting the model order and the best structural system poles. It enables a very good identification behaviour for noisy data sets as well as for high order, highly damped structures which allowed PolyMAX to stand as a potential new standard. 
A comparison between OMA and OBMA was performed by Di Lorenzo et al [17]on a wind turbine gearbox. Only the natural frequencies are identified experimentallyfor the two techniques. It was observed that the natural frequencies are identified as intervals which weremissing for the OMA technique and were not studied by the EMA.

Orlowitz and Brandt [18] studied an experimental comparisonbetween the EMA and the OMA on a simple Plexiglass plate. Tests are achieved under comparable boundary condition. They conclude that there is nosignificant difference in the estimated modal parameters obtained whether by theOMA and the EMA techniques.

In this study, three modal analysis techniques were studied experimentally and numerically by determining the natural frequencies, modal damping and the mode shapes. It used the EMA, OMA and OBMA techniques and appliedthem to a complex system of aback to back planetary gear test bench. The modal parameters of each techniques were extracted and compared.

Thus, the boundary conditions of each test were different from each other. While the test with the EMA was achieved on a stopped motor, those with OMA and OBMA were carried out under a running motorwhichmay explainthe high damping in the OMA and OBMA.

\section{1-Experimental setup:}

\section{1-1- Test bench description:}

A back to back planetary gear test bench was used in this research work. (Hammami et al[19]) and figure 1 shows its main components of this test bench. It consists of two identical planetary gears connected by two rigid shafts, supported by a rigid housing and an electrical motor. Each planetary gear set is made up of a ring, carrier sun and three identical planets. The first planetary gear set has a fixed ring and is called reaction gear while, the second one has a free ring and called test gear.

The two-gear sets were connected through two rigid shafts linking the suns and carriers; the inner one is called sun shaft and the external one is called carrier shaft.

A mass wasadded at the end of radial armand connected to the free ring so as toapply an external load.

The reaction and test planetary gears are similar and have the same size and shape of the gear teeth, number of teeth, contact ratio, and number of planets. There are also similar masses and inertiamoments of the sun carrier ring and planet gears.

Figure 1and table 1 show the experimental test bench and the basic dimensions, respectively.

The layout of the test bench and the instruments used are displayed in figure 2 .

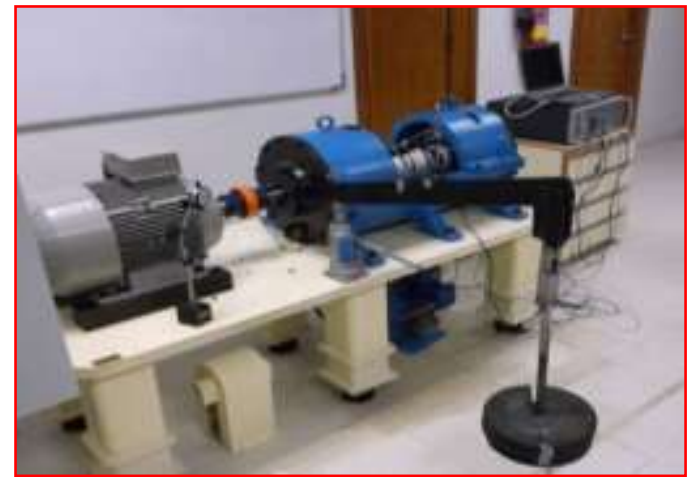

(a) 


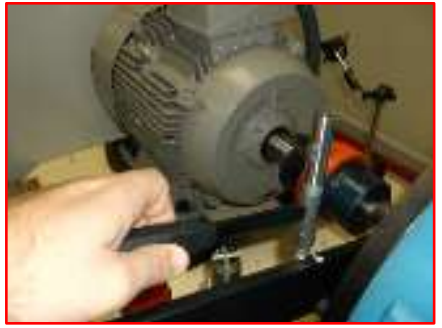

(b)

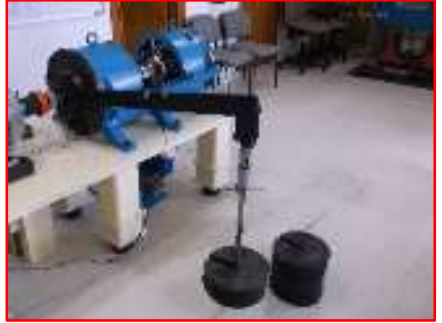

(c)

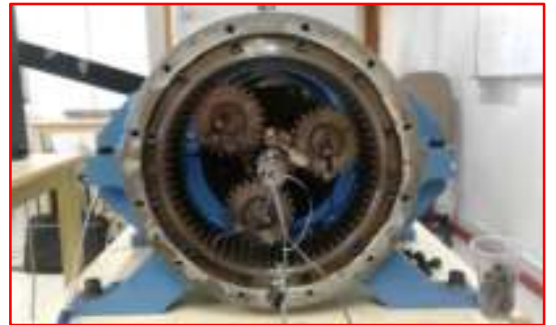

(d)

Fig.1.Experimental test bench : (a) general view (b) modal test application points (c) applied external load (d) planeraty gear

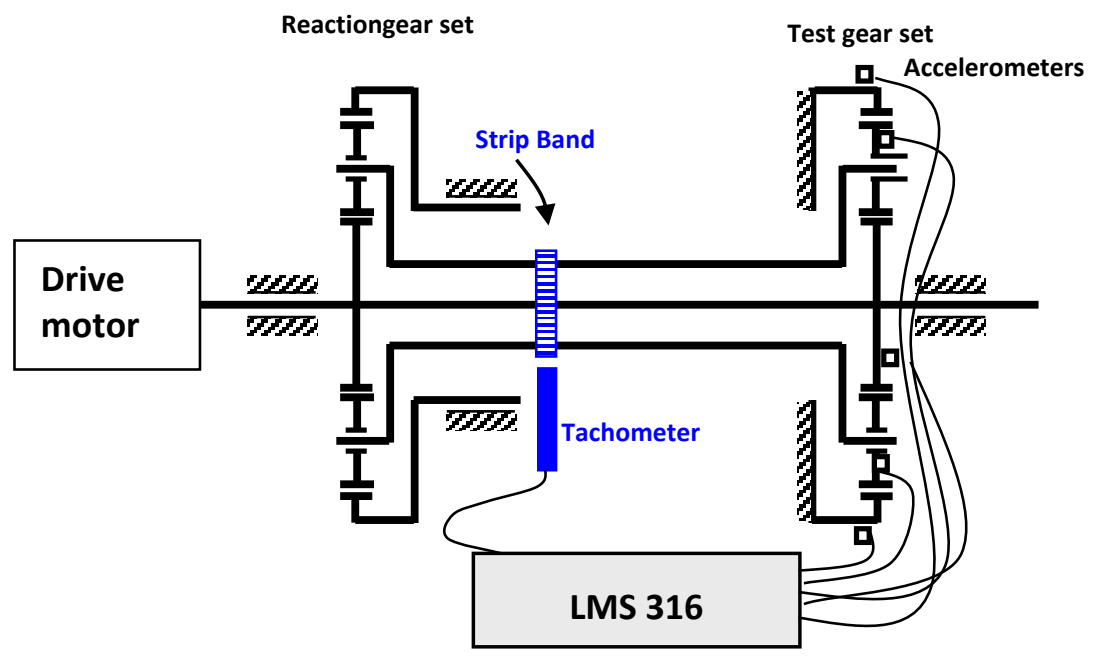

Fig. 2. Test bench instrument

Table1.Planetary gear basic dimensions

\begin{tabular}{|c|c|c|c|c|}
\hline & Sun & Planet (3) & Ring & Carrier \\
\hline Number of teeth & 16 & 24 & 65 & - \\
\hline Module & 0.00423 & 0.00423 & 0.00423 & - \\
\hline Pressure angle & 0.4621 & - & & \\
\hline Base diameters & 0.0614 & 0.0921 & 0.2494 & 0.1728 \\
\hline Tip diameters & 0.0699 & 0.1006 & 0.2579 & 0.1813 \\
\hline
\end{tabular}

\section{1-2-Vibration response measurements}

The primary objective of applying the EMA to the transmission set was to measure the independent motion of each planetary gear component.

Many analytical and numerical models guess the dynamic motion of each gear constitution. The experiments must have identical details as the numerical model to make for the comparison between the numerical and experimental results possible and more credible.

Tri-axial accelerometers are mounted in different locations to measure the rotational and translational vibration of the ring, carrier, sun and the three planets of the test gear.

The impact test was carried out on the arm in order to excite the rotational mode and on the planets and the sun of the test gear in order to excite the translational mode.

\section{1-3-Excitation method:}




\section{1-3-1-Impact hammer excitation:}

A $1 \mathrm{mV} / \mathrm{N}$ impact hammer, PCB 086B03 model excites the system at the arm fixed to the ring of the reaction gear set (figure 1-b). A plastic tip with added mass yields the spectral dynamic response of less than 1000 Hzbecause this type of hammer canexcite only the less than $1300 \mathrm{~Hz}$ bandwidth mode.

Impacts tests use standard techniques to calculate the frequency response from the measured time signals. The responses from ten hammer impacts are Root Mean Square(RMS) averaged to improve the data quality.

The coherence function was used as a data quality assessment tool which identifies how much of the output signal is related to the measured input signal.

A coherence close to 1 indicates that the measurements are repeatable; otherwise, they are not.

In our case the coherence is close to 1 along the frequency bandwidth but it can go below 0.5-0.6 in particular zones. In these zones, we cannot confirm the presence of natural frequencies. In fact,it is obvious that the signal-to-noise ratio is very low at the anti-resonance level. Then the measurements at frequency peaks will be completely noisy. For this reason, we find a virtually zero coherence at these frequencies.

In addition, the reduce of coherence can be explained by the complex path between the measurement point and the impact point.

The sampling parameters were adjusted for each test depending on the target response bandwidth. A sampling frequency fs $=1 \mathrm{kHz}$ with $N=1000$ samples per average is used to target low-frequency modes below $1000 \mathrm{~Hz}$ (plastic hammer tip with added mass). A force window was applied to the signal immediately after the impulse; Figure 3 shows the coherence function and the input random force,respectively.

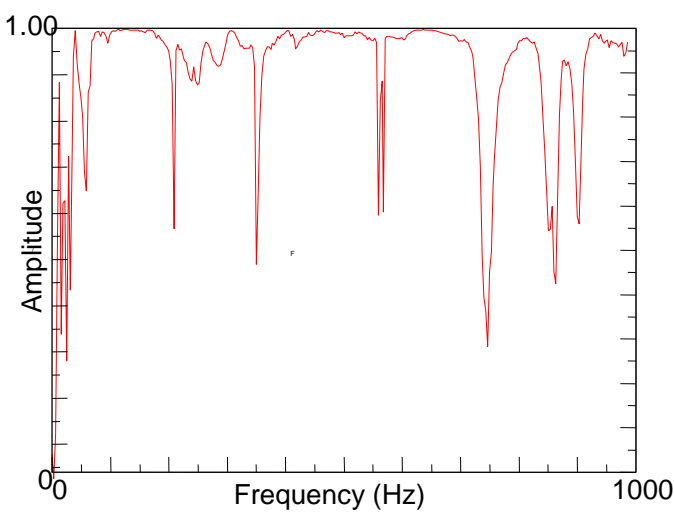

(a)

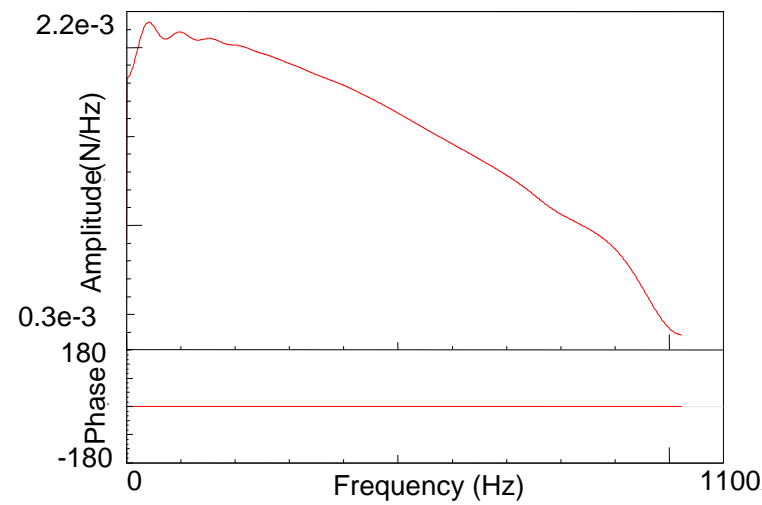

(b)

Fig.3. (a) Coherence function (b) force window of the hammer

\section{1-3-2-Dynamic excitation:}

An electric motor was connected to the sun's shaft to rotate both gear sets. The motor was controlled by a frequency inverter through starter software. The characteristics of the motor are shown in table 2.

Table 2.Motor characteristics

\begin{tabular}{|c|c|c|c|c|}
\hline Voltage (V) & Frequency (HZ) & Current (A) & Power (Kw) & Speed (tr/min) \\
\hline $400 \Delta$ & 50 & 29.5 & 15 & 1460 \\
\hline $690 \mathrm{Y}$ & 50 & 17.1 & 15 & 1460 \\
\hline
\end{tabular}


The operational measurements are divided into two parts: a stationary condition for an operational modal analysis and a run up condition for the order based modal analysis.

\section{1-4-Data acquisition and processing:}

Accelerometers were used to measure the vibrations in the different components. The acquired signals were processed with the software "LMS Test. Lab 15A impact testing" to obtain the frequency response functions.

The kinematic orientation of the planetary gear and the locations where the accelerometers were mounted are known and constant. The sensors wereequallyspaced by $180^{\circ}$ intervals for the different components except for the ring gear body where they are equally spaced by $90^{\circ}$, figure (4).

To measure the angular acceleration of the fixed ring. Four accelerometers are mounted and equally spaced (90 between two successive accelerometer). The tangential

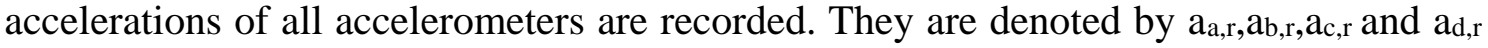
respectively. Then, the angular accelerations are computed according to equation (1).

To measure the angular acceleration of the carrier, sun and the three planets. Two accelerometers are mounted, and equally spaced (180 between two successive accelerometer). The tangential accelerations of all accelerometers are recorded. They are denoted by $\mathrm{a}_{\mathrm{a}, \mathrm{r}}, \mathrm{ab}, \mathrm{r}$ respectively.Then, the angular accelerations is computed according to equation (1).Figure 5 displays the instruments layout.

We focused on the tangential components of the acceleration because the radial components cancel each other [20], [21].

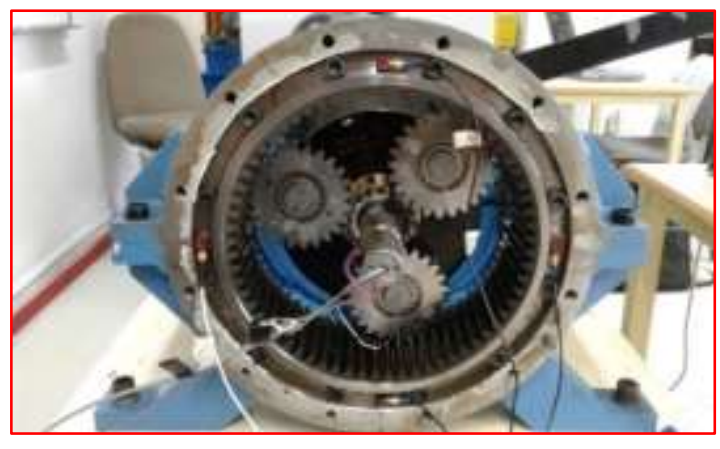

(a)

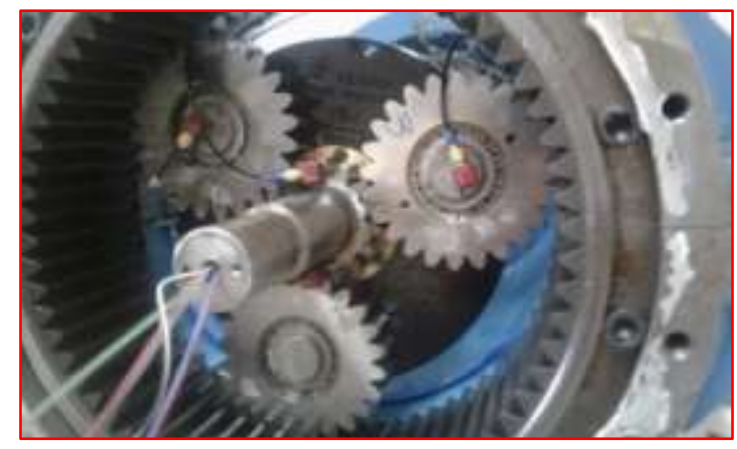

(b)

Fig.4. Accelerometers mounted (a) on the ring gear (b) on the sun and planets of the test ring

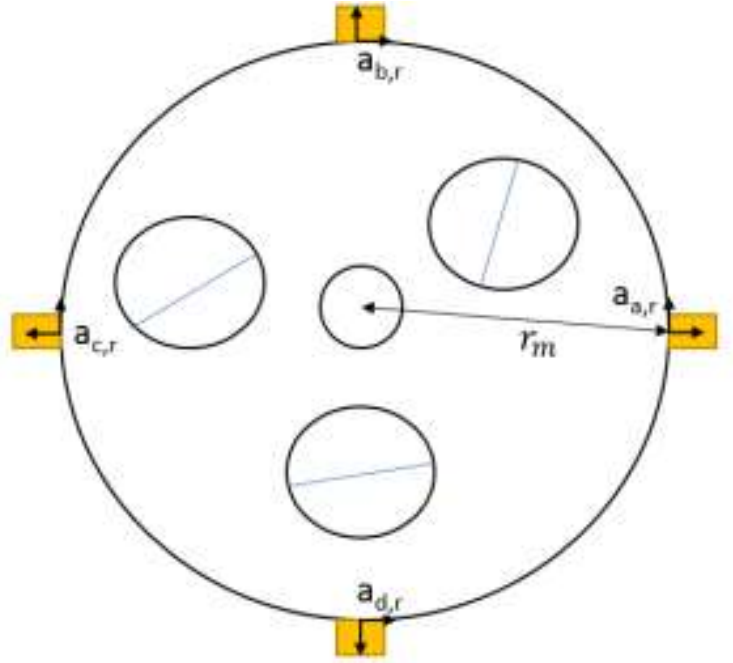

(a)

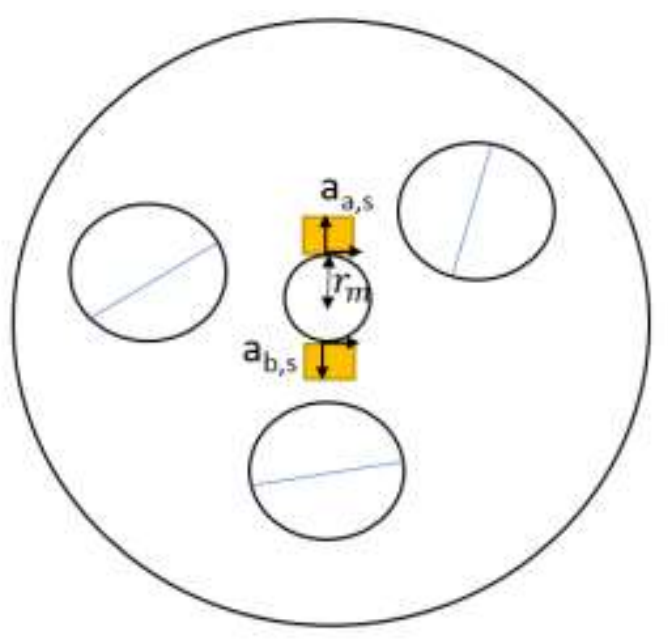

(b)

Fig.5.Instruments layout (a) on the ring (b) on the sun 
The angular acceleration $\ddot{\theta}_{r}$ of the ring gear body was collected by averaging the four accelerometer signals and dividing by the mounting ring's radius $r_{m, r}$ giving:

$$
\ddot{\theta}_{r}=\frac{a_{a, r}+a_{b, r}+a_{c, r}+a_{d, r}}{r_{m, r}}
$$

The angular accelerations $\ddot{\theta}_{i}$ of the other gear components (sun, planets, and carrier) $i$ werecollected by averaging the two accelerometer signals and dividing by the mounting radius $r_{m, i}$ giving:

$$
\ddot{\theta}_{i}=\frac{a_{a, i}+a_{b, i}}{r_{m, i}}
$$

\section{1-5-Modal parameter estimation:}

The estimated Frequency Response Functions (FRF), Cross Correlation Functions (CCF) and Order Functions (OF) were processed bya poly-reference modal parameter estimation method called PolyMAX. This method is a further evolution of the leastsquares complex frequency-domain (LSCF) estimation methodand a poly-reference version of the LSCF method[16]. The main benefits of this method are the facts that thesingular value decomposition SVD step to decompose the residues can be avoided and that closely spaced poles can be separated.

The PolyMAX method needs (FRFs) or (CCF) or (OF) as primary data and after that identifies a right matrix-fraction model.

$[H(\omega)]=[B(\omega)][A(\omega)]^{-1}$

$[H(\omega)]$ is the FRF matrix containing the FRFs between all $\mathrm{m}$ inputs and all 1 outputs.

The numerator row-vector polynomial of output $\mathrm{O}$ and the denominator matrix polynomial are defined as:

$$
\begin{aligned}
& \left\langle B_{O}(\omega)\right\rangle=\sum_{r=0}^{p} \Omega_{r}(\omega)\left\langle\beta_{\text {or }}\right\rangle \\
& \langle A(\omega)\rangle=\sum_{r=0}^{p} \Omega_{r}(\omega)\left\langle\alpha_{r}\right\rangle
\end{aligned}
$$

Where $\Omega_{\mathrm{r}}(\omega)$ are the polynomial basis functions and $\mathrm{p}$ is the polynomial order.

$\beta_{\text {or }}$ and $\alpha_{\mathrm{r}}$ are two polynomial coefficients

In this approach, the participation factors are available when constructing the stabilization diagram(Eq.6). From the rig right matrix-fraction model and after reducing the normal equations, the poles and modal participation factors are retrieved as the eigenvalues and eigenvectors of their companion matrix.

$$
[H(\omega)]=\sum_{i=1}^{n} \frac{\left\{v_{i}\right\}\left\langle l_{i}^{T}\right\rangle}{j \omega-\lambda_{i}}+\frac{\left\{v_{i}^{*}\right\}\left\langle l_{i}^{H}\right\rangle}{j \omega-\lambda_{i}^{*}}-\frac{L R}{\omega^{2}}+U R
$$

where $\mathrm{n}$ is the number of modes; $* *$ is the complex conjugate of a matrix; $\left\{v_{i}\right\}$ are the mode shapes; $l_{i}^{T}$ are the modal participation factors and $\lambda_{i}$ are the poles, which occur in complex-conjugated pairs and are related to the eigenfrequencies $\omega \mathrm{i}$ and damping ratios $\xi \mathrm{i}$ as follows:

$$
\lambda_{i}, \lambda_{i}^{*}=-\xi_{i} \omega_{i} \pm j \sqrt{1-\xi_{i}^{2} \omega_{i}}
$$


LR, UR are respectively the lower and upper residuals modelling the influence of the out-of-band modes in the considered frequency band.

This procedureallows constructing a stabilization diagram for increasing the model orders and using stability criteria for natural frequencies, damping ratios and modal participation factors.

The mode shapes were calculated from the eigenvectors corresponding to the selected poles.

\section{2-Analytical lumped-parameter model}

The planetary gear sets used in these experimentsare spur gears. These have motion in all degrees of freedom, so a three-dimensional model is appropriate to model. While some models consider only the gear rotational motion, others include the translation motion, as well. Kahraman[3] used a rotational lumped-parameter model planetary gear to provide the expressions of natural frequencies. Lin and Parker [5] consider a twodimensional model with rotations and translations and investigate the modal properties of planetary gears.

To obtain a good correlation between the numerical and experimental results a threedimensional model was adopted.

The test bench numerical model is presented in figure 6 .

The model is divided into twoblocks (reaction planetary gear(r) and test planetary gear). Each block consists of a ring (r) a carrier (c), a sun (s) and three planets (p1, p2, p3). These components are considered as rigid bodies with mass $\mathrm{m}_{i j}$ and inertiaI $\mathrm{I}_{i j}$. Each component is defined by 6 degrees of freedom. 3 translation $\mathrm{u}_{i j}, \mathrm{v}_{i j}, \mathrm{w}_{i j}$ and 3 rotations $\phi_{i j}, \Psi_{i j}, \theta_{i j}(\mathrm{i}=\mathrm{c}, \mathrm{r}, \mathrm{s}, \mathrm{p} 1, \mathrm{p} 2, \mathrm{p} 3 ; \mathrm{j}=\mathrm{r}, \mathrm{t})$.

The rotations $\phi_{i j}, \Psi_{i j}$ and $\theta_{i j a r e}$ replaced by their corresponding translational gear mesh displacements as in[22]:

$$
\rho_{i j x}=R b_{i j} . \phi_{i j} \rho_{i j y}=R b_{i j} . \Psi_{i j} \rho_{i j z}=R b_{i j} \cdot \theta_{i j}(\mathrm{i}=\mathrm{c}, \mathrm{r}, \mathrm{s}, \mathrm{p} 1, \mathrm{p} 2, \mathrm{p} 3 ; \mathrm{j}=\mathrm{r}, \mathrm{t}) \text {. }
$$

Where: $R b_{i j}$ is the base circle radius for the sun, ring, planet, and the radius of the circle passing through the planet centres for the carrier.

Each component is supported by a bearing with a stiffness $\mathrm{k}_{i j k}$ wherei=c, r,s,p1,p2, p3; $\mathrm{j}=\mathrm{r}$, tin direction $\mathrm{k}=\mathrm{u}, \mathrm{v}, \mathrm{w}, \phi, \Psi, \theta$.

The sun and the ring arerespectively connected to the planets by the gear mesh stiffness $\mathrm{K}_{r p r l}, \mathrm{~K}_{r p r 2}, \mathrm{~K}_{r p r 3}$ and $\mathrm{K}_{s p r l}, \mathrm{~K}_{s p r 2}, \mathrm{~K}_{s p r 3}$ in the reaction gear set and by the gear mesh stiffness $\mathbf{K}_{r p t 1}, \mathbf{K}_{r p t 2}, \mathbf{K}_{r p t 3}$ and $\mathbf{K}_{s p t 1}, \mathbf{K}_{s p t 2}, \mathbf{K}_{s p t 3}$ in the test gear set. The two planetary gear sets are connected through the sun shaft and the carrier shaft. Each shaft is characterized by an axial stiffness $\mathrm{k}_{\mathrm{sa}}$, kca; flexural stiffness $\mathrm{k}_{\text {sf }}, \mathrm{k}_{\text {cfand }}$ torsional stiffness kst,kct. 


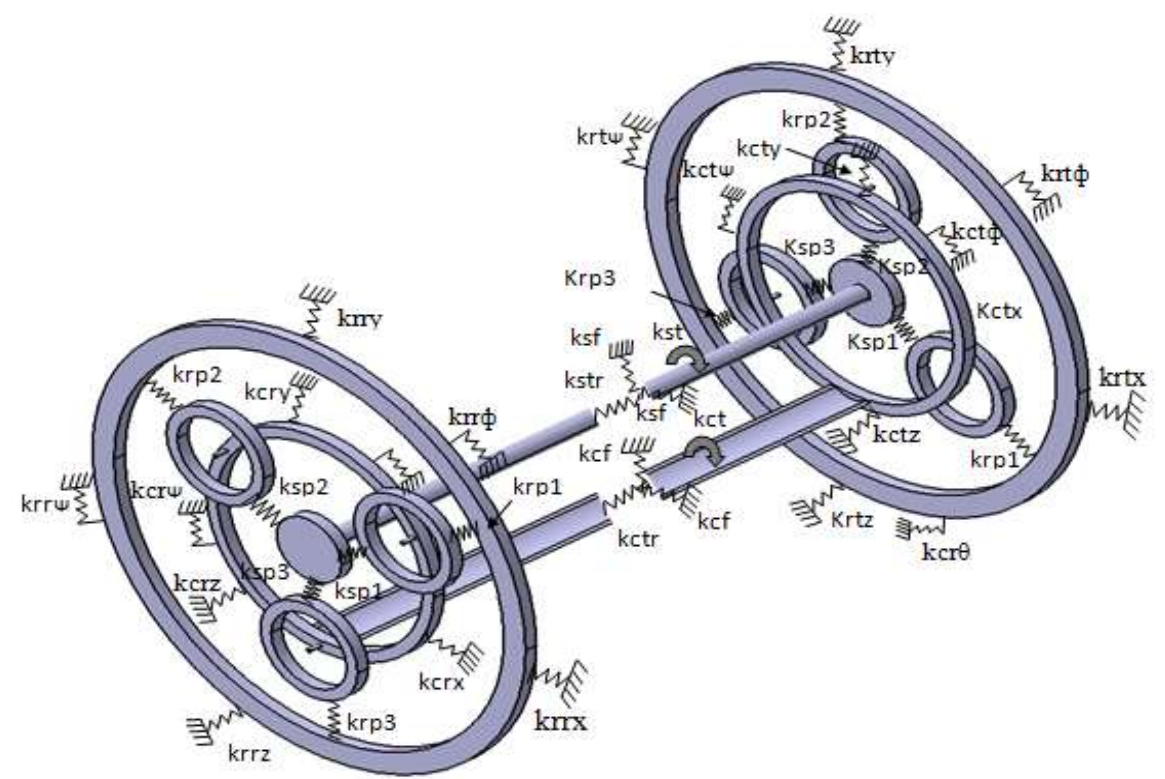

Fig.6. Model of planetary gear

Following the procedure given in [22], it is possible to write the equation of motion as:

$$
M \ddot{q}+C \dot{q}+\left(K_{b}+K_{e}(t)\right) q=F(t)
$$

Where $\mathrm{q}$ is the vector degree of freedom defined as

$\mathrm{q}=\left\{\begin{array}{l}q_{r} \\ q_{t}\end{array}\right\}$

$\mathrm{q}_{\mathrm{r} \text { is }}$ the degree of freedom vector of the reaction gear set (r) and $\mathrm{q}_{\mathrm{t}}$ is the degree of freedom vector of the test gear set $(\mathrm{t})$.

$$
\begin{aligned}
& q_{r}=\left\{U_{c r}, V_{c r}, W_{c r}, \rho_{c x r}, \rho_{c y r}, \rho_{c z r}, U_{r r}, V_{r r}, W_{r r}, \rho_{r x r}, \rho_{r y r}, \rho_{r z r}, U_{s r}, V_{s r}, W_{s r}, \rho_{s x r}, \rho_{s y r}, \rho_{s z r},\right. \\
& \left.U_{1 r}, V_{1 r}, W_{1 r}, \rho_{1 x r}, \rho_{1 y r}, \rho_{1 z r}, U_{2 r}, V_{2 r}, W_{2 r}, \rho_{2 x r}, \rho_{2 y r}, \rho_{2 z r}, U_{3 r}, V_{3 r}, W_{3 r}, \rho_{3 x r}, \rho_{3 y r}, \rho_{3 z r}\right\} \\
& q_{t}=\left\{U_{c t}, V_{c t}, W_{c t}, \rho_{c x t}, \rho_{c y t}, \rho_{c z t}, U_{r t}, V_{r t}, W_{r t}, \rho_{r x t}, \rho_{r y t}, \rho_{r z t}, U_{s t}, V_{s t}, W_{s t}, \rho_{s x t}, \rho_{s y t}, \rho_{s z t},\right. \\
& \left.U_{1 t}, V_{1 t}, W_{1 t}, \rho_{1 x t}, \rho_{1 y t}, \rho_{3 z t}, U_{2 t}, V_{2 t}, W_{2 r t}, \rho_{2 x t}, \rho_{2 y t}, \rho_{2 z t}, U_{3 t}, V_{3 t}, W_{3 t}, \rho_{3 x t}, \rho_{3 y t}, \rho_{3 z t}\right\}
\end{aligned}
$$

$\boldsymbol{M}$ denotes the mass matrix, $\boldsymbol{K}_{b}$ is the bearing and shaft stiffness matrix, $\boldsymbol{K}_{\boldsymbol{e}}(\boldsymbol{t})$ is the time varying stiffness matrix and $\boldsymbol{F}(\boldsymbol{t})$ denotes the external force vector applied to the system. The planet sets are modelled as identical and equally spaced.

All the matrices are defined in the appendix of [23].

$\mathrm{C}$ denotes the proportional damping matrix expressed by:

$$
C=\alpha M+\beta K
$$

Where $\alpha$ and $\beta$ are two constants [24].

Table 3shows the lumped-parameters of the studied planetary gear test bench.

Table 3. Planetary gear and shafts parameters. 


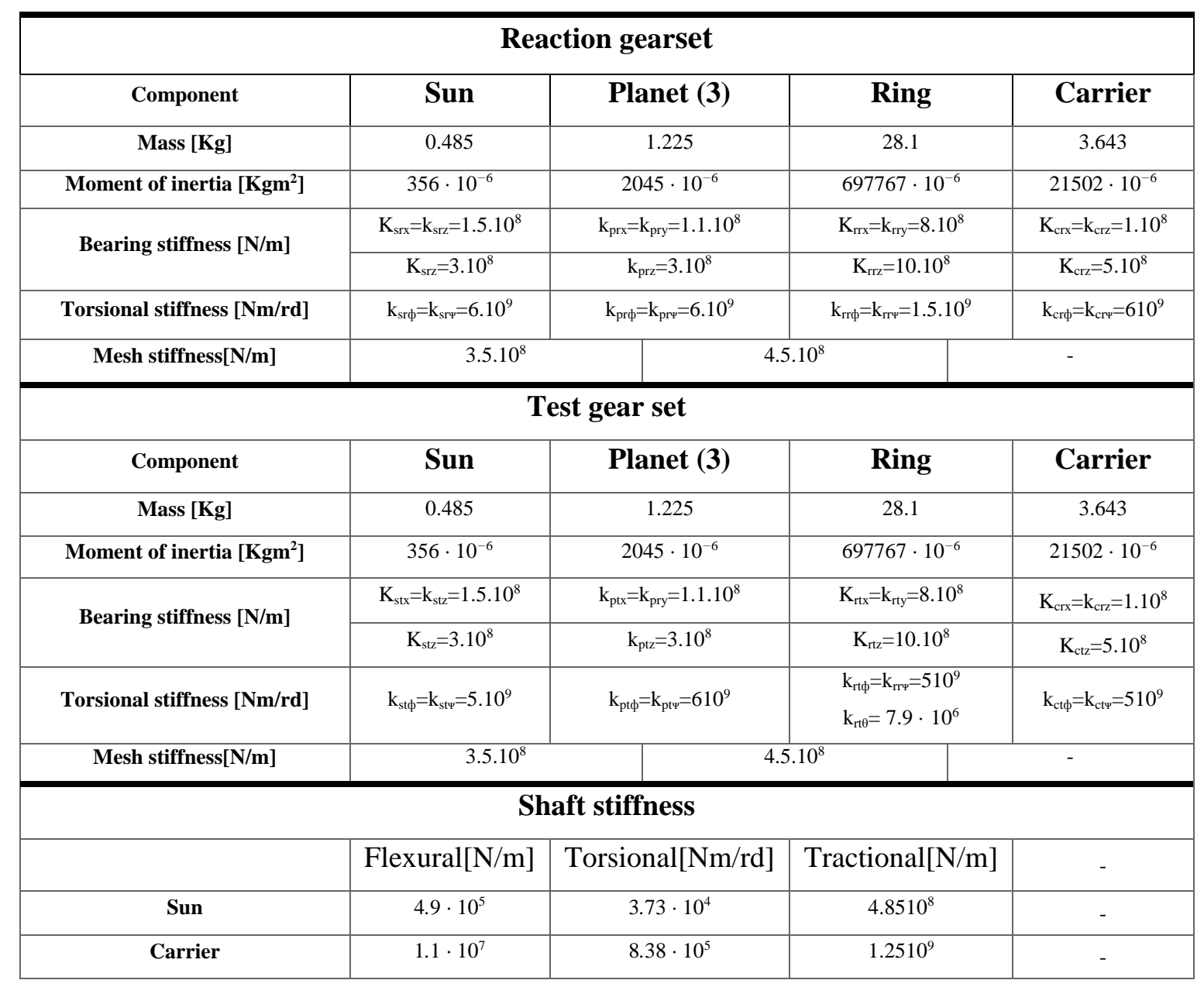

\section{3-Results:}

In this section, the experimental and numerical results of the EMA, OMA and OBMA techniques were investigated and compared.

The EMA test was performed when the motor was in stopping situation but OMA and OBMA tests were achieved when the motor was running.

The experiments were carried out with the same load level used for EMA (300N.m)

For each technique, the modal parameters in the frequency range below $1000 \mathrm{~Hz}$ were extracted. The natural frequencies and modal damping were determined using the stabilization diagram.

In Figure 7, an example of stabilization diagram from the EMA test is shown together with an averaged frequency response function as a simple mode indicator function.

Only stable poles are selected on the diagram before building an auto Mac matrixin ordertoinvestigate the real mode.

The Modal Assurance Criterion (MAC) was usedto correlate the experimental with numerical mode shapes.

To compute the MAC, one degree of freedom per element was considered in the numerical model and experimental data.

Not stable pole Stable pole 


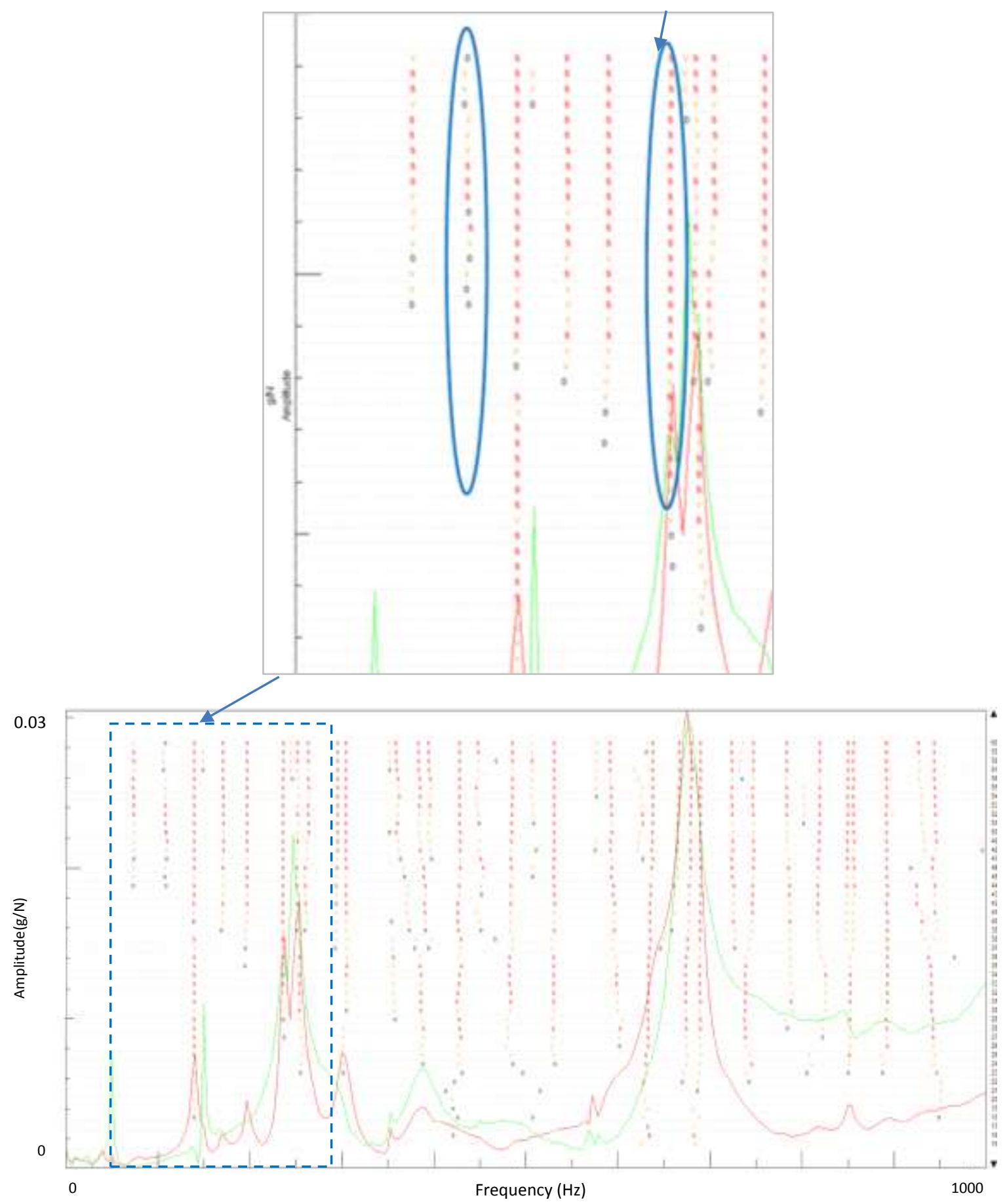

Fig.7. Stabilization diagram

The stabilization diagram should contain a good FRF and a mode indicator function (MIF) (green) is more helpful at identifying resonances.

The use of criteria for selecting stable pole is as follow:

The model size is increased until poles stabilize. Then, the $2^{\text {nd }}$ or $3^{\text {rd }}$ "s" are selected after the stabilization of the pole.

The selected pole yields the determination of mode. Then, the auto Mac matrix is obtained. Based on auto Mac matrix and other criterion such as MPD (modal phase deviation), MPC (modal phase collinearity) and the scatter, we can conclude to the real mode.

\section{3-1-Experimental modal analysis:}




\section{3-1-1-Frequency response function:}

The impact hammer testing provides sufficient excitation throughout the fixture mode frequency range, and the impact locations are available to excite these modes.

The impacts were achieved by the hammer on the arm to excite the rotational modesand on the horizontal directions of the sun and planets to excite the translational modes.

The EMA test was performed with a stopped test bench but the lateral plate which supports the sun's shaft is mounted when the excitations were on the arm and dismounted when the excitations were on the planets and the sun.

The natural frequencies were identified in the different component such as sun, ring, planets and carrier.

The obtained modes were estimated by using the stabilization diagram as well as thedamping and natural frequencies.

20 modes were identified: 16 rotational and 4 translational.For each mode, the modal damping and natural frequency were determined.

The rotational modes are characterized by arotational motion of-ring, carrier and sun components and in-phase motion of planets.

The translational modes are characterized by a translational motion of the sun, carrier and ring.

While the number of planets is three, only two were observed (rotational and translational) and the third (planet mode) was remarqued to be missing [25].

The results obtained experimentally are compared to those issued from the lumped parameters model.

Figure 8 shows the frequency response function measured on the sun carrier, the planet and the ring of the test gear.

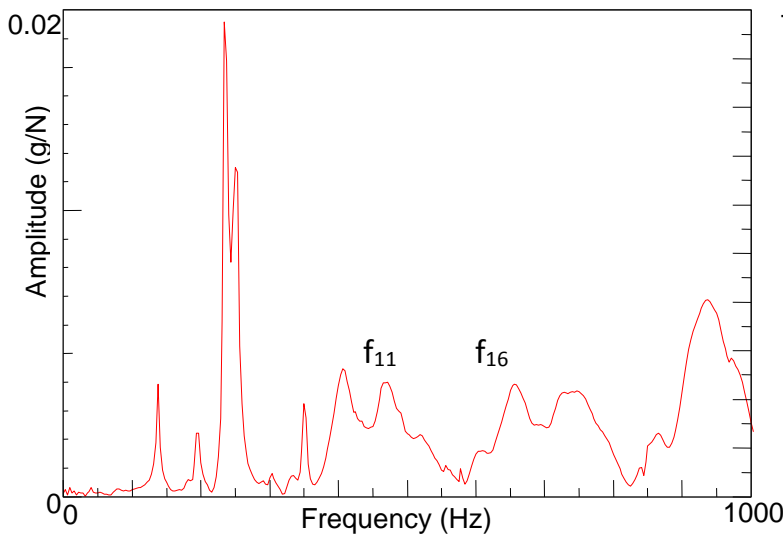

(a)

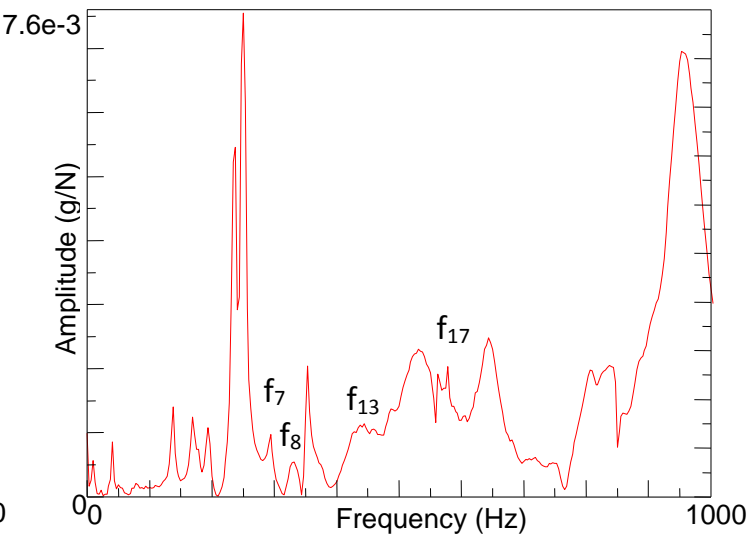

(b) 


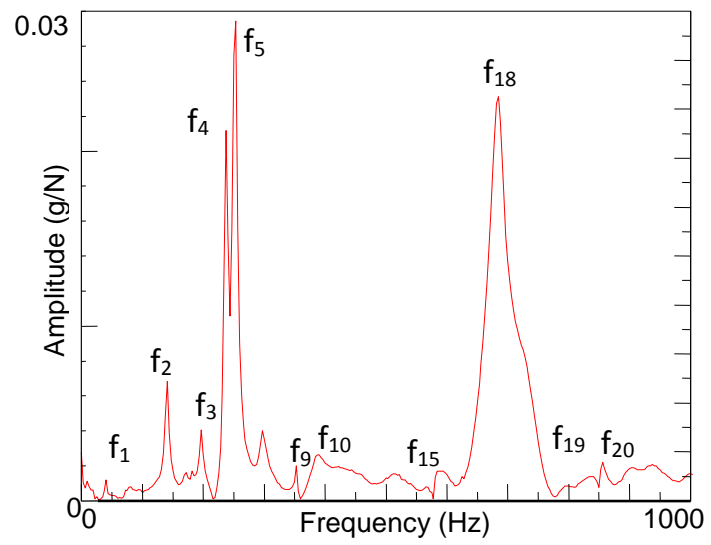

(c)

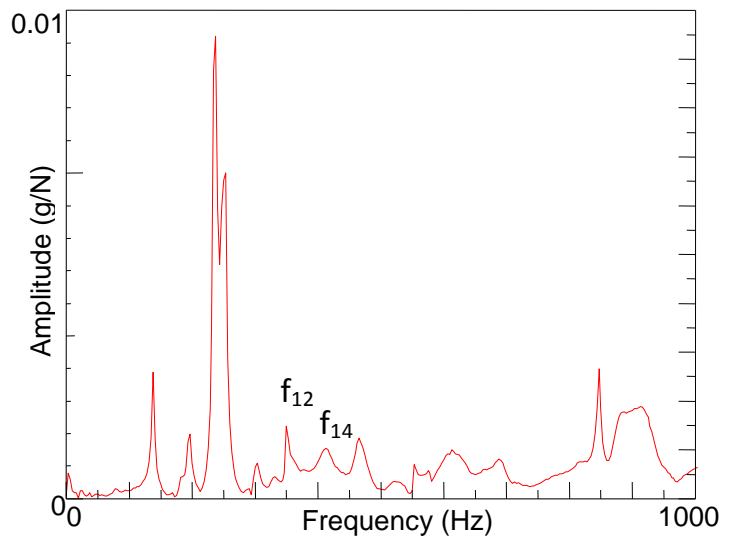

(d)

Fig.8. Frequency response function measured on the: (a) Carrier (b) Planet 1(c) Ring (d) Sun

As a result, we can notice that the dynamic response in various degrees of freedom is qualitatively and quantitatively different.

Most of the natural frequencies appear on the ring which is the fixed element.

\section{3-1-2-Natural frequencies damping and modes:}

Table4displays the comparison between the natural frequencies determined from the experimental impact tests and the numerical model, the multiplicity of each mode (only for the analytical model) and the damping ratio. 
Table 4: Modal properties obtained during thedynamic testing.

\begin{tabular}{ccccccc}
\hline Mode & Multiplicity & Type & Experimental & Numerical & Error (\%) & Damping ratio (\%) \\
\hline $\mathbf{1}$ & 1 & $\mathrm{R}$ & 76 & 77 & 1,30 & 0.77 \\
$\mathbf{2}$ & 1 & $\mathrm{R}$ & 136 & 154 & 11,69 & 1.36 \\
$\mathbf{3}$ & 1 & $\mathrm{R}$ & 169 & 172 & 1,74 & 1.61 \\
$\mathbf{4}$ & 1 & $\mathrm{R}$ & 195 & 197 & 1,02 & 1.49 \\
$\mathbf{5}$ & 1 & $\mathrm{R}$ & 251 & 241 & $-4,15$ & 1.06 \\
$\mathbf{6}$ & 2 & $\mathrm{~T}$ & 301 & 291 & $-3,44$ & 1.57 \\
$\mathbf{7}$ & 2 & $\mathrm{~T}$ & 325 & 320 & $-1,56$ & 1.41 \\
$\mathbf{8}$ & 1 & $\mathrm{R}$ & 352 & 342 & $-2,92$ & 0.38 \\
$\mathbf{9}$ & 1 & $\mathrm{R}$ & 378 & 384 & 1,56 & 2.00 \\
$\mathbf{1 0}$ & 1 & $\mathrm{R}$ & 406 & 413 & 1,69 & 2.04 \\
$\mathbf{1 1}$ & 1 & $\mathrm{R}$ & 436 & 436 & 0,00 & 2.09 \\
$\mathbf{1 2}$ & 1 & $\mathrm{R}$ & 466 & - & - & 2.06 \\
$\mathbf{1 3}$ & 2 & $\mathrm{~T}$ & 526 & 531 & 0,94 & 2.16 \\
$\mathbf{1 4}$ & 1 & $\mathrm{R}$ & 558 & 552 & $-1,09$ & 0.08 \\
$\mathbf{1 5}$ & 1 & $\mathrm{R}$ & 578 & 592 & 2,36 & 0.65 \\
$\mathbf{1 6}$ & 1 & $\mathrm{R}$ & 604 & 618 & 2,27 & 2.19 \\
$\mathbf{1 7}$ & 2 & $\mathrm{~T}$ & 687 & 697 & 1,43 & 0,96 \\
$\mathbf{1 8}$ & 1 & $\mathrm{R}$ & 755 & 720 & $-4,86$ & 1.28 \\
$\mathbf{1 9}$ & 1 & $\mathrm{R}$ & 783 & - & - & 1.65 \\
$\mathbf{2 0}$ & 1 & $\mathrm{R}$ & 803 & 815 & 1,47 & 1.57 \\
\hline $\mathbf{2}$ & 1 & & & &
\end{tabular}

\section{3-1-3- Modal assurance criterion:}

To estimate the quality of the obtained mode shapes, theModal Assurance Criterion (MAC) values were calculated. First of all, the auto Mac is computed separately from the numerical and experimental mode shape to investigate the validity of the estimated modes. Then, the MAC between both experimental and numerical is determined to compare two mode shapes obtained from two different modal parameter estimation processes" (numerical modal analysis and experimental modal analysis). The MAC between two mode shape vectors was defined as in[26]:

$$
M A C=\operatorname{MAC}\left(\{\hat{D}\}_{j},\{D\}_{l}\right)=\frac{\left|\{\hat{D}\}_{j}^{T} \cdot\{D\}_{l}^{T}\right|}{\left(\{\hat{D}\}_{j}^{T} \cdot\{\hat{D}\}_{j}^{*}\right)\left(\{D\}_{l}^{T} \cdot\{D\}_{l}^{*}\right)}
$$

Where:

$\{\hat{D}\}$ and $\{D\}$ are respectively the numerical and experimental mode shapes.

The results for different mode sets combinations are displayed in Figure 9. The MAC values of MAC equal to 1meanthat the two modes are perfectly correlated; while a MAC valueof 0means the two vectors are perfectly orthogonal.

Using the MAC, all the numerically and experimentallyobtainedmodes arecompared. 
The MAC computation was performed with the same degree of freedom in the numerical model and the experimental data. The determination of the angular acceleration using equations (1) and (2) for each component and the use of the torsional lumped parameter model allow the building of the modal shapes for all the modes.

For the Mac indicators, we chose only the modes which are correlated. The other modes where the Mac is lower than 1 were neglected.

Five out of the twenty modes were identified, and their mode shapes were drawn.

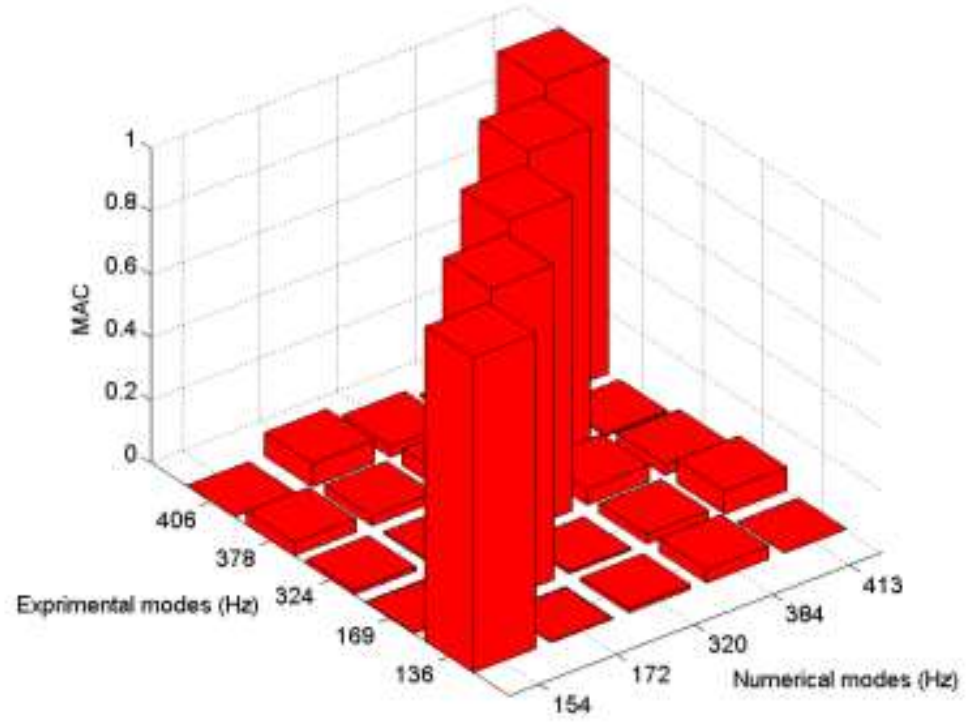

Fig.9.MAC matrices from the mode shapes of the experimental and numerical modes

\section{3-1-4-Mode shapes}

Table5shows the five first rotational modes validated by the Modal Assurance Criterion and the comparaison between the exprimental and numerical modes.

The mode shapes are plotted on the test planetary gear where the measurement are taken.

The experimental mode shapes were designed from each degree of freedommagnitude and phase in the impacts tests, while the analytical model provided the mode shapes directly from the eigenvalue problem. 
Table 5.Comparison between numerical and experimental mode shapes.

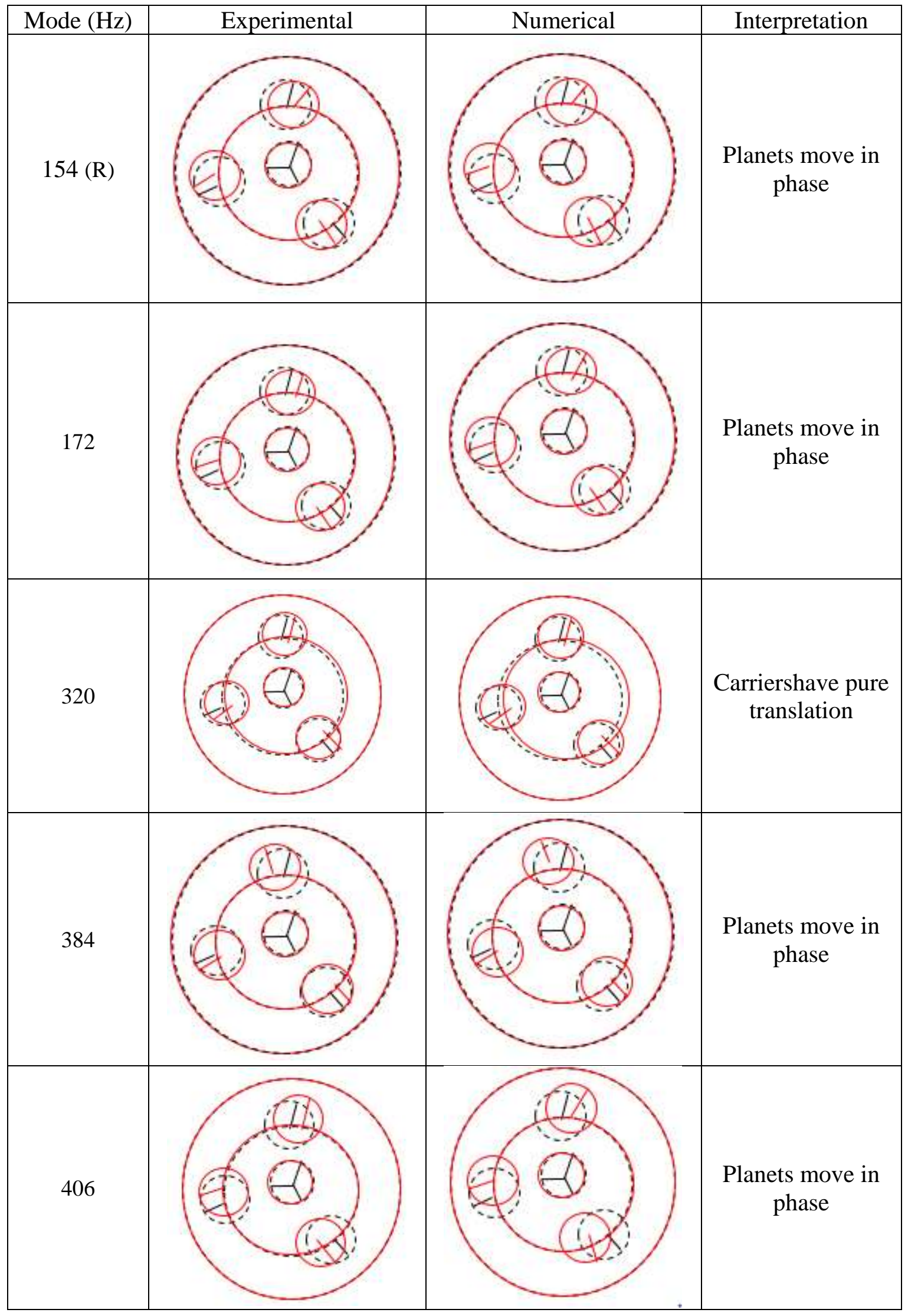

Based on the MAC criteria, five modes are correlated. four rotational modes (154 $\mathrm{Hz}, 172 \mathrm{~Hz}, 384 \mathrm{~Hz}, 406 \mathrm{~Hz})$ and one translational mode $(320 \mathrm{~Hz})$ 
The experimental and numerical mode shapes plotted are similar. We can notice that all the planets on the test gear set have the same modal deflexion and move in phase for the rotational modes. Besides, the carriers on the test gear set have a pure translation in the translational mode.

\section{3-2-Operational modal analysis:}

\section{3-2-1-Measurement and Analysis System:}

The operational modal analysis method has become widely used for the rotatingmachinerytocharacterize their modal proprieties.

The purpose of this procedure was to extract the modal frequencies, damping and mode shapes from data taken under operating conditions.For our gear transmission case, it wasunder the influence of its internal excitation caused by a time varying mesh stiffness.

OMA is used specifically in applications where the inputs cannot be measured.It is available when using only responses like acceleration signals. In fact, in our study, the motor was running at $1498.5 \mathrm{rpm}$.

For a planetary gearbox, the mesh frequency is computed according to the following equation:

$$
f_{m}=\frac{Z_{s} Z_{r}}{Z_{s}+Z_{r}} \frac{N}{60}
$$

So,the structure is excited by the gear mesh frequency $\mathrm{f}_{\mathrm{m}}=320 \mathrm{~Hz}$. The same conditions were used for the simulation.

The sensors were mountedonly on fixed ring tomeasure the instantaneousacceleration. Figures 10 and 11 showthe acceleration measured on fix ringsin both time and frequency domains.

Figure10showsa modulation of the signal measured on fixed ring on one period of rotation of carrier $(\mathrm{Tc}=0.2 \mathrm{~s})$, Inalpolat and Kahraman [27]. This modulation is explained by the modulated force due to the carrier rotation. Thesystem was excited by the mesh frequency $(320 \mathrm{~Hz})$ and its harmonics.

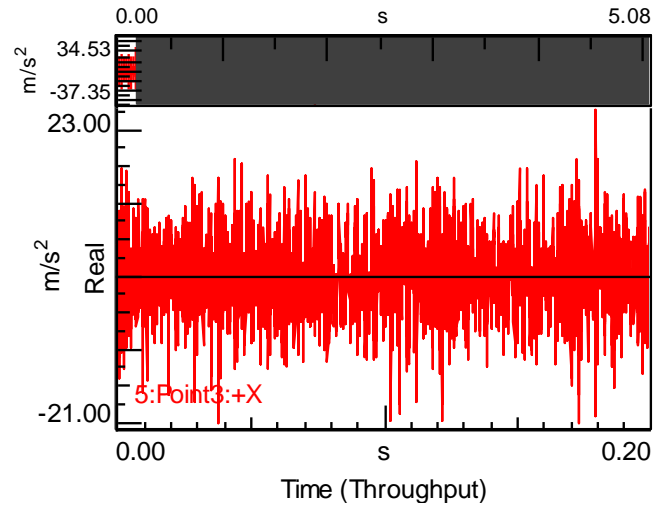

(a)

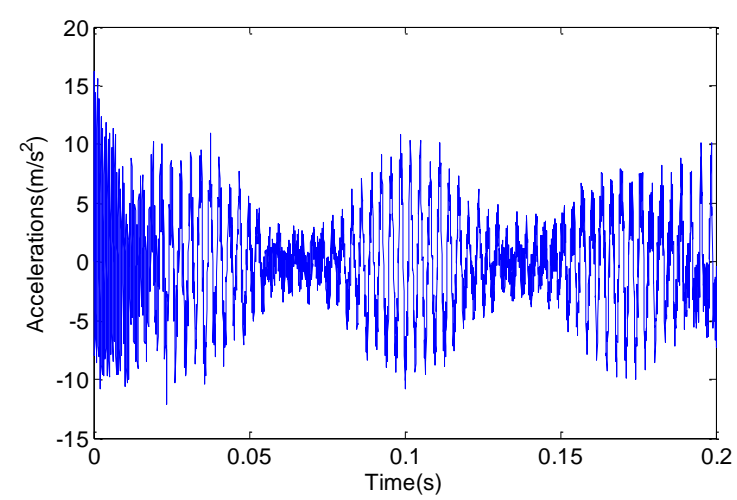

(b)

Fig.10. Time response measured on fix ring (a) Experimental (b) Numerical 


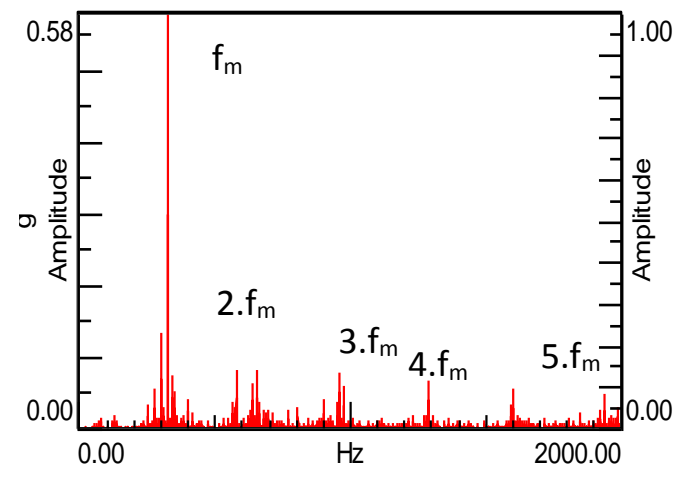

(a)

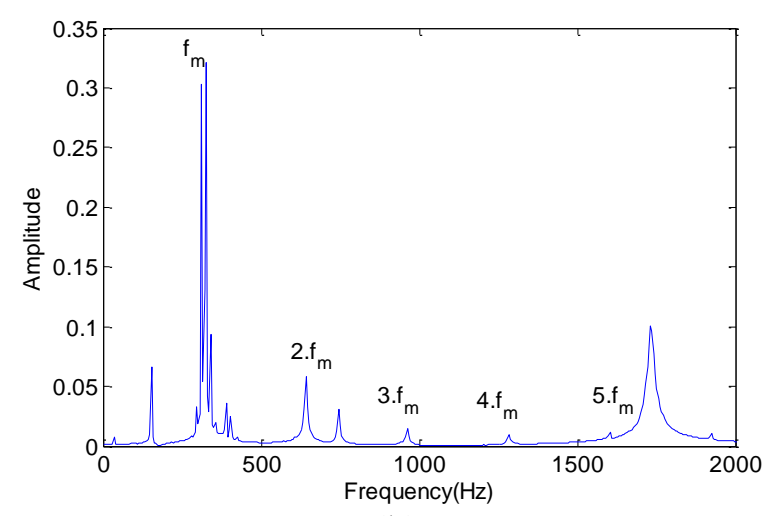

(b)

Fig. 11. Spectra of acceleration on the fixed ring (a) Experimental (b) Numerical

A clear modulation appears on figure $11 \mathrm{~b}$, which is slightly different compared to figure 10.a. This figure which is noisy, and the modulation is concealed. They are explained also by the effect of the force due to the rotation of carrier which has a period $\mathrm{Tc}=0.2 \mathrm{~s}$ and frequency $\mathrm{fc}=5 \mathrm{~Hz}$. In addition, an individual effect of each planet on the accelerometer will be assumed for a duration $\mathrm{Tc} / \mathrm{N}(\mathrm{N}=3$ : number of planets). So, when a planet $\mathrm{i}$ approaches to the location of the accelerometer, its effect will increase for the first $\mathrm{Tc} / 2 \mathrm{~N}$ time period, reaching its maximum when a planet $\mathrm{i}$ approaches the location of the accelerometer and then is diminished to zero at the end of the next $\mathrm{Tc} / 2 \mathrm{~N}$ time period. This phenomenon repeated sequentially. In addition, the difference between curves can be noticed on the acceleration spectra. The accelerations spectra of the fixed ring (Fig.11.a) are clearly observed to be dominated by the mesh frequency $(320 \mathrm{~Hz})$ and its harmonics. Thus, some sidebands appear on these spectra on the 3.n.fc (n: integer). These sidebands can be explained by the force due to the carrier which was considered in the numerical model or by the presence of some mounting defects.

Spectra on the m.fc (m: integer) appears only the experimental curves, these sidebands are related to the gravity of the carrier on the dynamic response planetary gear. The frequencies of the carrier appear in the response spectrum of the reaction ring along of the frequency axis which is neglected during simulation. However, only the mesh frequency appears on the numerical spectra (figure 11.b).

\section{3-2-2-Power spectral density function:}

After measuring the fixed rings time response, the OMA techniques wereapplied to extract the modal properties.

For these OMA techniques, The PolyMAX method techniques were applied throughPower Spectral Density (PSD) functions.

The PSDis defined as the Fourier transform of the correlation functions. The most popular non-parametric spectrum estimate is the so-called weighted averaged periodogram (also known as modified Welch's periodogram). This Welch's method can be determinedbycomputing theDiscrete Fourier Transforms DFT of the outputs [28]:

$$
Y(w)=\sum_{k=0}^{N-1} w_{k} y_{k} \exp (-j w k \Delta t)
$$

Where $\mathrm{N}$ is the length of $\mathrm{yk}$. $\mathrm{yk}$ and $\mathrm{Y}(\mathrm{w})$ are the input signal and output signal respectively, wk: denotes the time window and $t$ is the time increment.

The cross-correlation between two responses y1 and y2 is the product of the complex conjugate of the discrete Fourier transforms DFT of y1, which is the reference, and the 
DFT of y2 in the frequency domain.In fact, the inverse DFT of thisproduct produces a biased correlation function; Therefore, the correlations function between signal $\mathrm{y}_{1}(\mathrm{t})$ and $\mathrm{y}_{2}(\mathrm{t})$ becomes [29]:

$$
E_{21}(m)=\frac{1}{\sum_{k=0}^{N-1}\left|w_{k}\right|^{2}} Y_{1}(w) Y_{2}^{H}(w)
$$

The Cross Power Spectral DensityCPSD functions were determined experimentally and numerically and the different modal parameters wee extracted using the stabilization diagram.

Figures12a and bshow the CPSDon the fixed ringobtained by the experimental test and the numerical model,respectively.

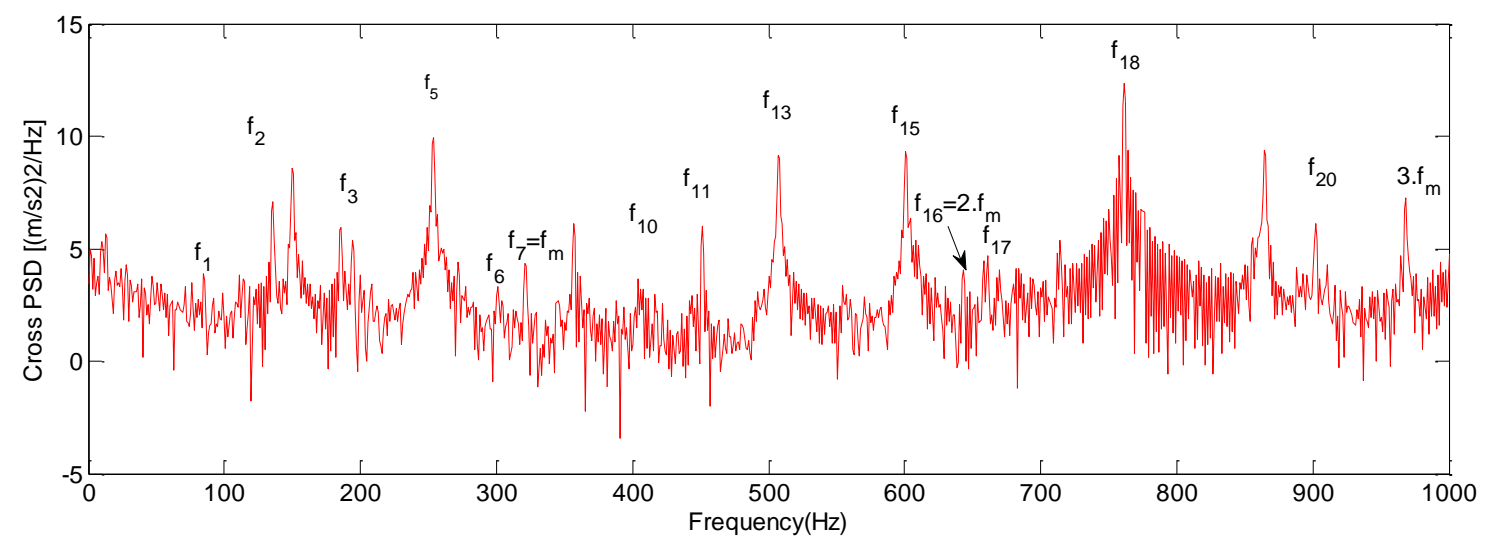

(a)

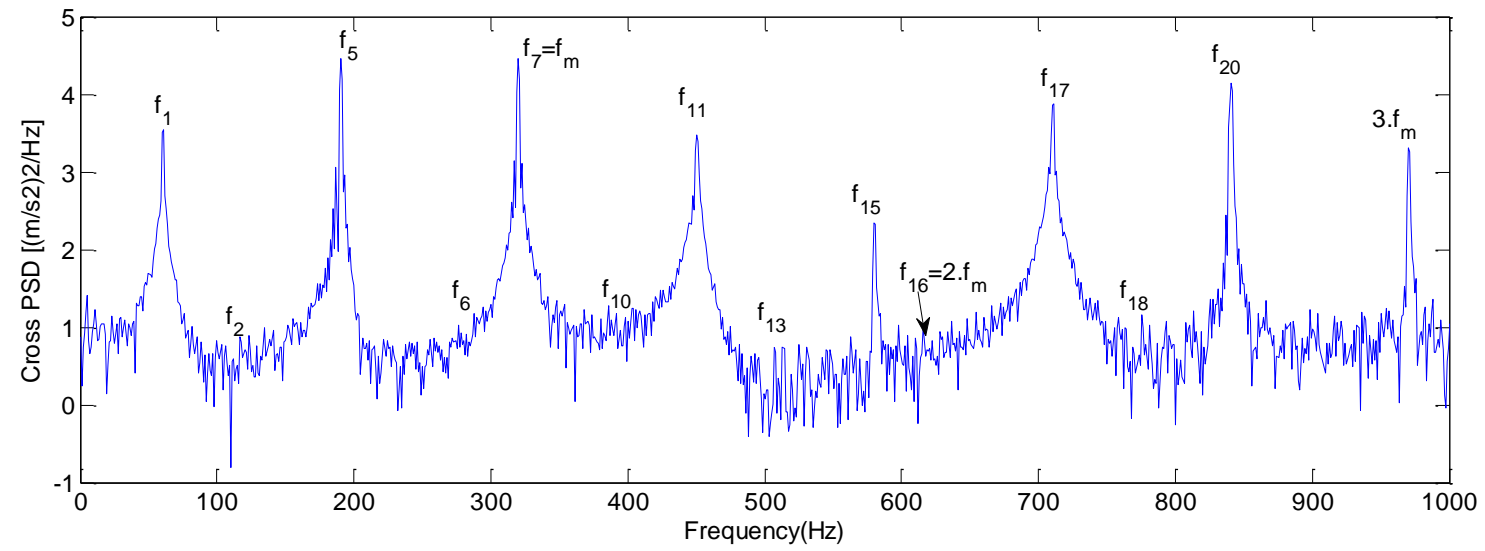

(b)

Fig.12. Cross power function determined on the fixed ring (a) Experimental (b) Numerical

The harmonic $(320 \mathrm{~Hz}$ and multiples) appears on both experimental and numerical figure.

Natural frequency peaks appear in both of experimental and numerical CPSD curves. The difference between these is noticed on amplitude explained by the difference founded on accelerations. For the frequency, the experimental CPSD contains many natural frequencies then the numerical CPSD. this due to different phenomena such as the white noise, the effect of temperature as well as the elastic coupling which links the motor shaft to the gear shaft. 


\section{3-2-3-Natural frequency damping and modes:}

Just like the previously used procedure in the experimental modal analysis (EMA), and by using the cross-power function, the modal properties were extracted.

Thirteenmodes were extracted with the associated multiplicity, modal damping and natural frequencies.

Some modes $\left(\mathrm{f}_{3}, \mathrm{f}_{4}, \mathrm{f}_{8}, \mathrm{f}_{9}, \mathrm{f}_{12}, \mathrm{f}_{14}, \mathrm{f}_{19}\right)$ are missing because they could not be excited in a stationary condition and since the boundary conditions changed when we moved from EMA to OMA tests.

The error percentages are lower than those of the experimental modal analysis.

Table6 displays the different extracted modesas well as the natural frequencies and the modal damping.

Table 6. Modal parametersduringrunning condition.

\begin{tabular}{cccccc}
\hline Mode & Multiplicity & Experimental & Analytical & Error $(\%)$ & Damping $(\%)$ \\
\hline 1 & 1 & 74 & 75 & $-1,35$ & 3,34 \\
2 & 1 & 129 & 132 & $-2,33$ & 3 \\
3 & 1 & 248 & 260 & $-4,84$ & 3,11 \\
4 & 2 & 298 & 300 & $-0,67$ & 3,42 \\
5 & 2 & 322 & 323 & $-0,31$ & 3,01 \\
6 & 1 & 394 & 391 & 0,76 & 3,27 \\
7 & 1 & 432 & 436 & $-0,93$ & 3,51 \\
8 & 2 & 540 & 521 & 3,52 & 2,29 \\
9 & 1 & 570 & 592 & $-3,86$ & 3,11 \\
10 & 1 & 629 & 618 & 1,75 & 3 \\
11 & 2 & 643 & 649 & $-0,93$ & 3,12 \\
12 & 1 & 747 & 781 & $-4,55$ & 2,85 \\
13 & 1 & 888 & 910 & $-2,48$ & 3,07 \\
\hline
\end{tabular}

The results displayed in table 6prove accurately the value of the error for each mode. Thisphenomenon is caused by themesh stiffness variation on the modal proprieties. This fact was highlighted by Mbareket al[23] who investigated experimentally and numerically the influence of meshing stiffness variation on natural frequencies. Moreover, it can be noticed through the table that there aresome missing modes. This can be explained by the fact that there are some modeswhich arenot excited in stationary conditions. For this reason, another type of OMA has to be studied.

\section{3-3-Order based modal analysis: 3-3-1-Order tracking:}

The second operational modal analysis type is the order based modal analysis technique. This technique allows the determination of modal proprieties during run up or run-down tests based on an order based Polymax.

The variation of speed during run up is controlled by the frequency converter Micromaster 440 and by using a led tachymeter with encoder zebra.

The encoder zebra or the strip bands contains 130 black bands which are all equally spaced. The strip bands are obtained through a macro.

The encoder zebra may produce some error when we mounted it on the shaft.

The encoder zebra was glued and rolled on the shaft (fig.13). This method may produce some error due to the fact that the both extremity of the encoder zebra are matched. 
The following figure shows a photo of zebra encoder mounted on the carrier shaft.

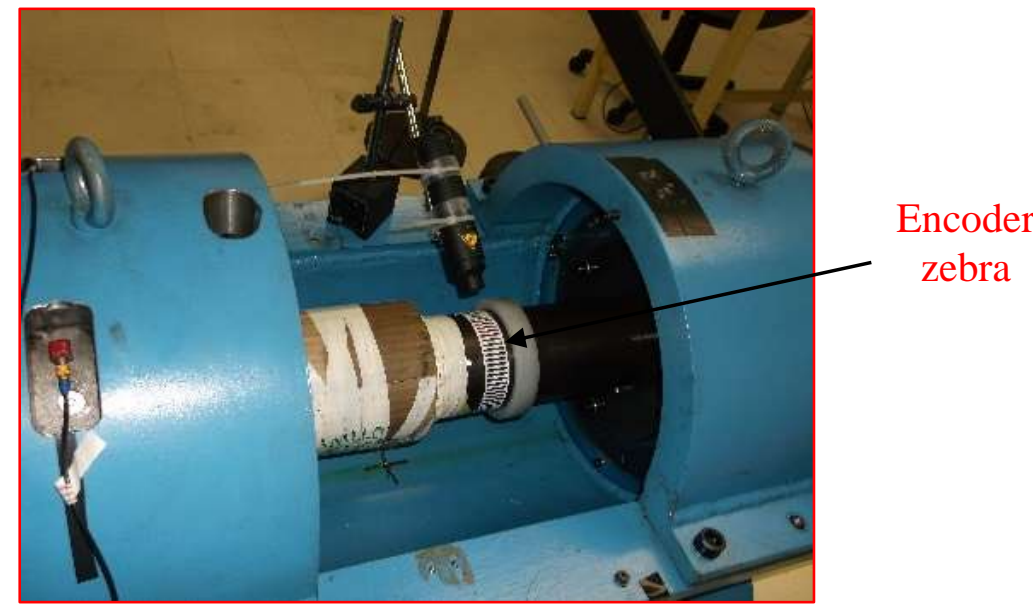

Fig.13.Encoder zebra and tachymeter

An order tracking method was used during this test. There are several order tracking methods such as Time Domain Sampling-Based Fast Fourier TransformOrder Tracking, angledomain, Vold-Kalman (VK) Filter-Based and Time Varying Discrete Fourier [30]. In our case, we used aspecial-order tracking method. The idea was to perform an OMAon tracked orders instead of considering the spectra. The angle domain was one of the techniques used during this experimental test.The very well-known order tracking method which is widely used in commercial software is based on angular resampling. Data are acquired with a uniform $\Delta t$ and then resampled to the angle domain using an adaptive digital resampling algorithm. The result of the technique is that the uniform $\Delta t$ data become uniformly spaced angle data. The amplitude and phase estimates of the orders were obtained by processing these data with a Discrete FourierTransform (DFT) instead of an FFT for computational flexibility in performing the transform without being restricted to a power of two numbers of samples.

In order to perform the time domain data to angle domain data transformation, a reference signal has to be selected to define the time instant at which the uniform angular intervals have been spaced. Typically, this signal is considered to be the tachometer signal measured on a reference shaft of the operating machine. The kernels of the Fourier transform were reformulated as shown in Eqs. (13) and (14), where om is the order which is being analyzed:

$$
\begin{gathered}
a_{n}=\frac{1}{N} \sum_{n=1}^{N} x(n \Delta \theta) \cos \left(2 \pi o_{m} n \Delta \theta\right) \\
b_{n}=\frac{1}{N} \sum_{n=1}^{N} x(n \Delta \theta) \sin \left(2 \pi o_{m} n \Delta \theta\right)
\end{gathered}
$$

\section{3-3-2-Order based modal analysis}

The system dynamic behavior is simulated and compared to the experimental results issued from the test ring.

For the run-up test, the mesh stiffness period decreases when the speed increase (Khabou et al., [31], Viadero et al., [32] Hammami et al. [14]). Figure (14) shows the evolution of ring-planet and sun-planets mesh stiffnesses.

To determine the computation of the exact frequency for the orders of interest, an accurate tachometer signal is needed.

Figure 15 shows the tachometer signal determined during run-up. 


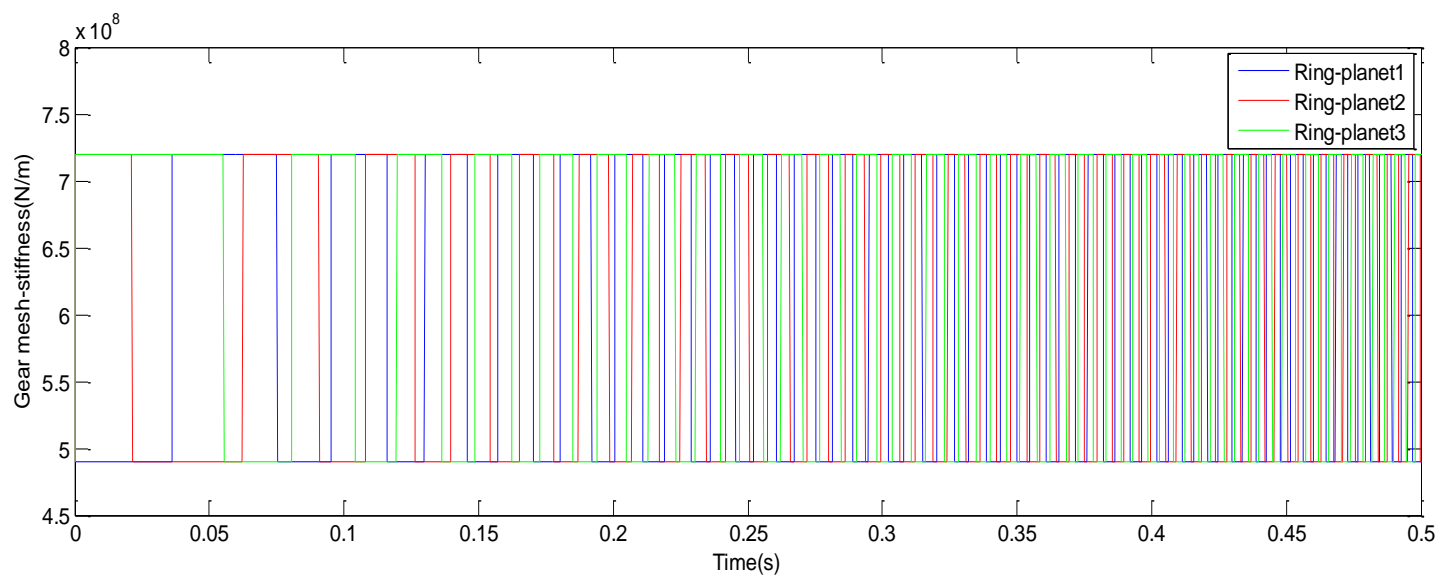

(a)

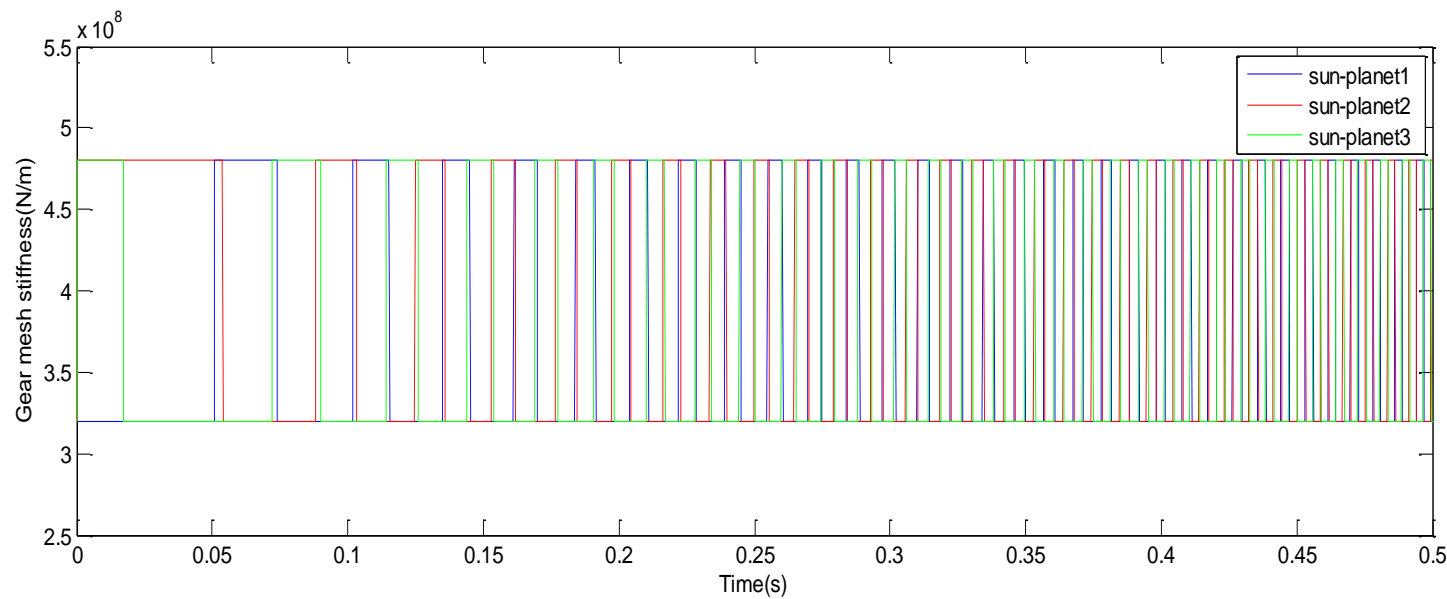

(b)

Fig.14. Gear mesh stiffness function: (a) ring-planet (b) sun-planet

This phenomenon is shown on the time response of the acceleration measured on the fixed ring through the increase of vibration with time (see figure (16)).

During this test, the meshing stiffness function excites the system in non-stationary conditions and short time Fourier transform issuedto process the acceleration signals. Figure 17displays the Short Time Fourier Transform (STFT) obtained for the measured acceleration on the fixed ring gear.

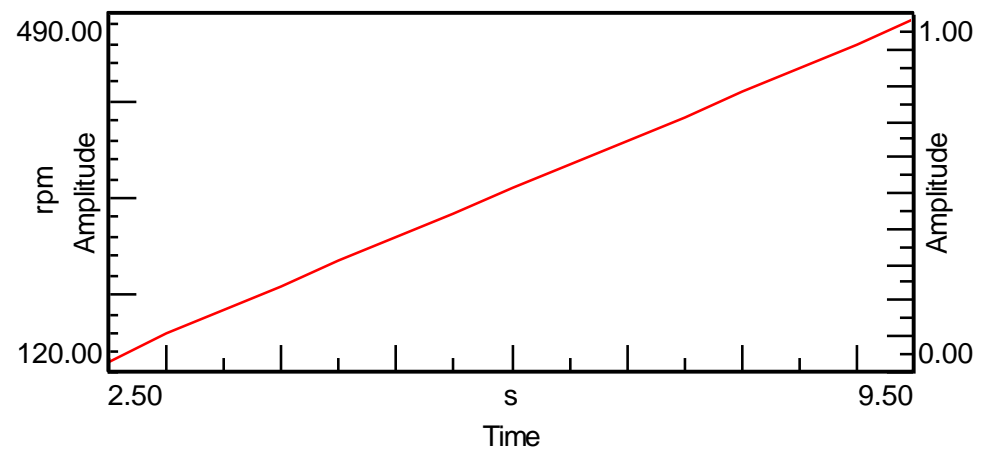

Fig.15. Tachometer signal 


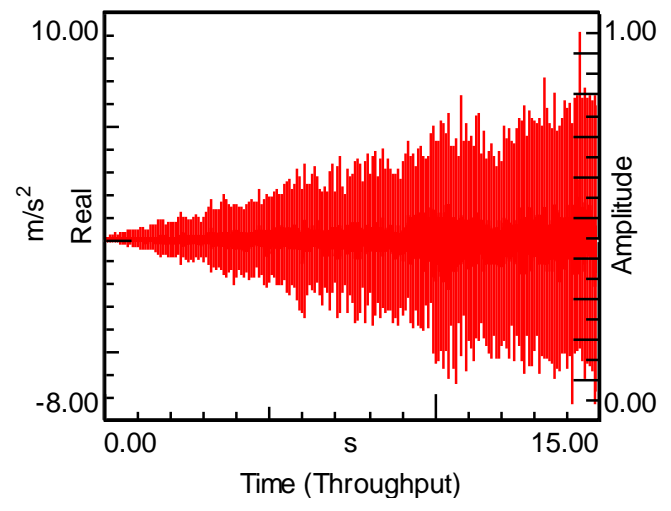

(a)

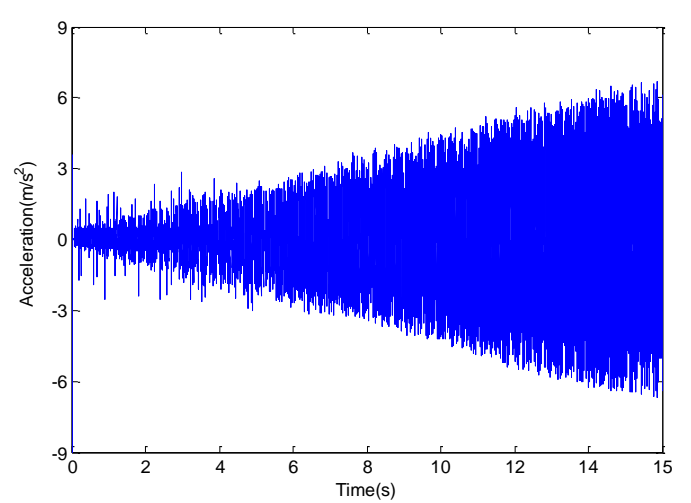

(b)

Fig. 16. Acceleration of the fixed ring: (a) experimentaland (b) numerical

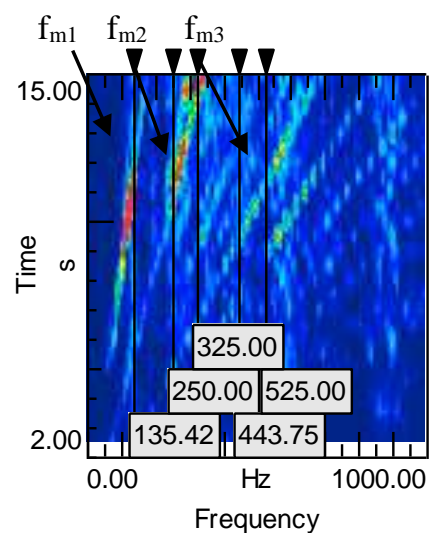

(a)

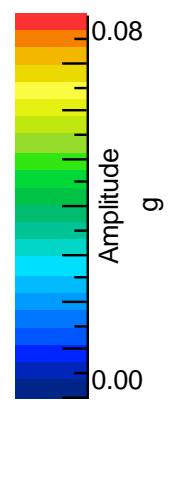

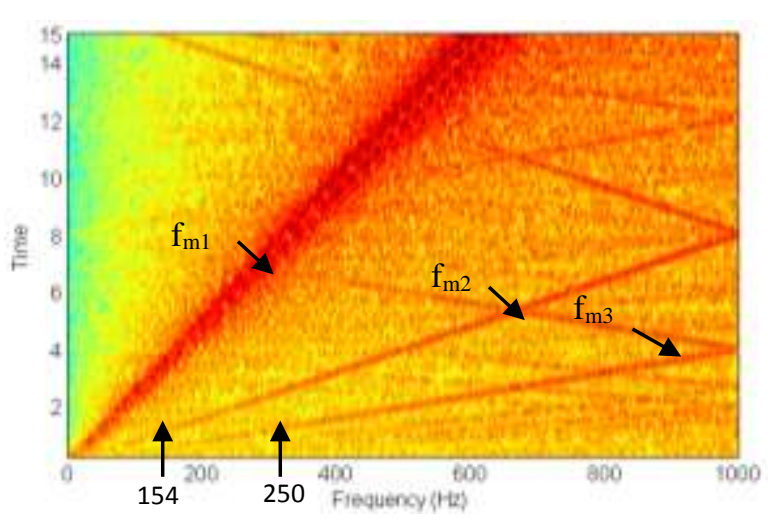

(b)

Fig.17.STFT on the fixed ring (a) experimental and (b) numerical

The noticed inclined lines prove the meshing frequency increase during run up and the vertical line shows some natural frequencies. There are also some zoneswhere the higher amplitude corresponds to someof the system natural frequencies.

The first and the second order were selected because the motor was running at 1300 rpmduring the run up test. The frequency associated to this run up test is equal to 540 $\mathrm{Hz}$.

The orders are shown on figure 18; the vertical lines indicate orders 1 and 2 with their harmonics.

As mentioned, the frequency bandwidth associated to this run up test is equal to $540 \mathrm{~Hz}$. The frequency at which a rotating system is operating can be calculated from an order and the rotational speed (expressed in rpm) via the Equation below:

$$
\text { Frequency }=\frac{(\text { order }) \cdot r p m}{60}
$$

Frequency and orders are really both the same: a measure of events over an observation frame:

- Frequency - Number of events per unit of time.

- Order - Number of events per revolution.

If the time and revolutions can be related for a rotating system, then the same phenomenon can be expressed as either a frequency or an order. Thus, knowing the 
revolutions per minute (rpm) of a rotating system allows frequency and order to be related to each other.

The order is computing according to the following equation:

$$
\begin{gathered}
\text { gear ratio }=\frac{z_{s}+z_{r}}{z_{s}} \\
\text { speed out }=\frac{\text { speed } \text { In }}{\text { ratio }} \\
\text { Order }=\frac{\text { freq.rot.In }}{\text { freq.rot.out }}
\end{gathered}
$$

Order response are 5,10,15,20,25 ...

The order should be multiple.In our case, the tachymeter detects only 12.88 corresponding to (15) and 25,25 corresponding to (25). Due to the vibration issued from the test bench, the tachymeter can move and the accurateness of the encoder zebra, can make a variation on mesh order.

Figure18showsthe order tracking map.

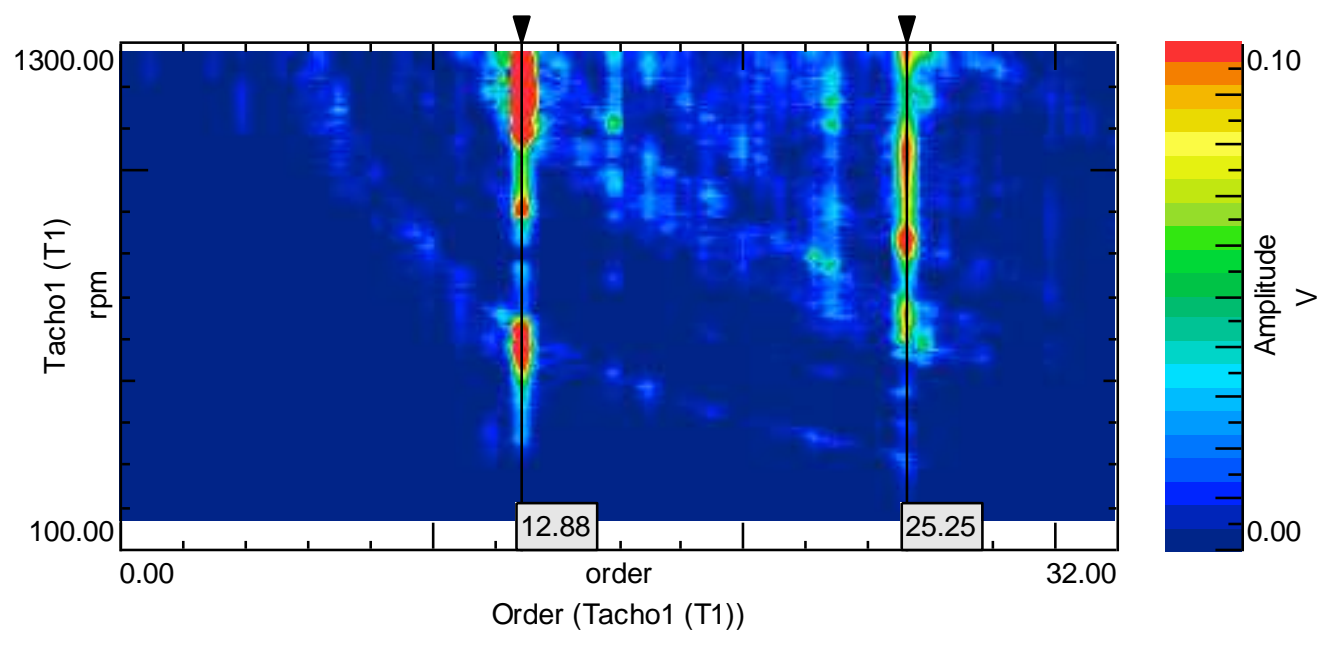

Fig.18. Order map

The most interesting orders are highlighted from figure 15 . They correspond to order 12.88 , which is the $1^{\text {st }}$ gear mesh frequency and 25.25 which is the $2^{\text {nd }}$ gear mesh frequency of the test gear. Then, the order tracking is presented by examining in detail this order and ignoring all the others. This phenomenon is called order tracking. The order resolution was set from 0.01 for a maximum order equal to 32 .

Figure 19shows the two first selected orders measured on the test gear ring. 


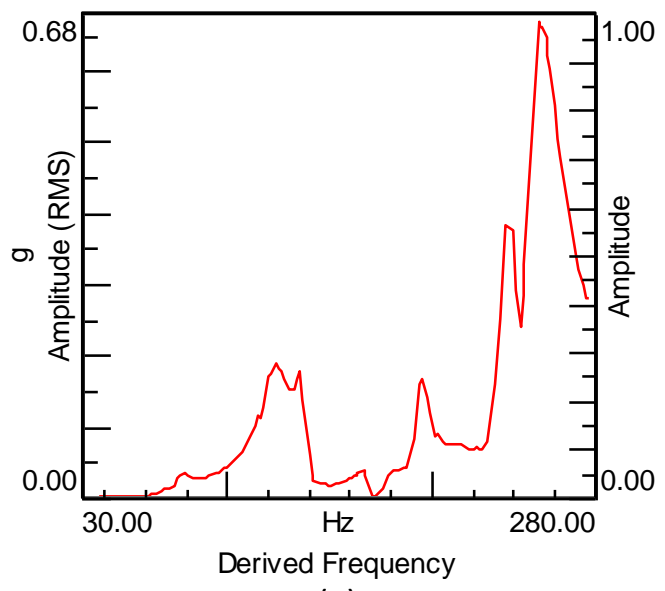

(a)

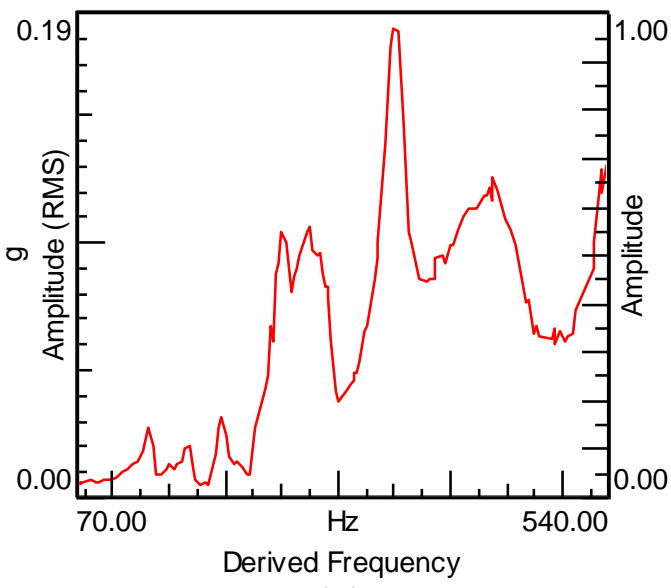

(b)

Fig.19.Order function (a) Order1 (b) Order2

Figure 19shows the extracted order for the measurement which is the test ring during the run up test.

While examining figure 19, some peaks can already be identified. Even the Polymax modal parameter estimation has been applied to these orders to extract the modal parameters.

\section{3-3-3-Natural frequency, damping and mode:}

The order based Polymax and stabilization diagram, the modal parameters are extracted. 13 modes are identified: 10 rotational and 3 translational,

Table 7 shows a comparison between the natural frequencies obtained numerically and experimentally during the run up test. There are some differences between the achieved experiments and the analytical model results.

Table7.Modal properties during the run up test.

\begin{tabular}{ccccc}
\hline Mode & Experimental & Analytical & Error (\%) & Damping ratio (\%) \\
\hline $\mathbf{1}$ & 72 & 77 & 6,49 & 3,2 \\
$\mathbf{2}$ & 125 & 154 & 18,83 & 3.6 \\
$\mathbf{3}$ & 159 & 172 & 7,56 & 3,3 \\
$\mathbf{4}$ & 191 & 197 & 3,05 & 3,7 \\
$\mathbf{5}$ & 250 & 241 & $-3,73$ & 3 \\
$\mathbf{6}$ & 294 & 291 & $-1,03$ & 3,41 \\
$\mathbf{7}$ & 325 & 320 & $-1,56$ & 3,13 \\
$\mathbf{8}$ & 354 & 342 & $-3,51$ & 3,5 \\
$\mathbf{9}$ & 375 & 384 & 2,34 & 3,76 \\
$\mathbf{1 0}$ & 404 & 413 & 2,18 & 3,7 \\
$\mathbf{1 1}$ & 441 & 436 & $-1,15$ & 3,29 \\
$\mathbf{1 2}$ & 471 & - & - & 3,15 \\
$\mathbf{1 3}$ & 521 & 531 & 1,88 & 3,41 \\
\hline
\end{tabular}

The frequency error is low, and the modal damping is higher than those obtained by the EMA.

The natural frequencies are identified in the frequency bandwidth [0-540 Hz] because the motor speed variation from 0 to $1300 \mathrm{rpm}$ during the run up tests. 


\section{4-Comparison between different modal analyses:}

The comparison between the different techniques is presented through contrastingthe natural frequency modal damping and the random error.

Table8showsa comparison between the obtained natural frequencies and the modal dampingusing the three techniques.

It can be observed that the natural frequency found inthe experimental modal analysis isalmostlikethat obtained by the order based modal analysis. However, some natural frequencies were remarked to be missing for the operational modal analysis.

The natural frequencies change is due to the evolutionof temperature in the inner component as well as the variation of the boundary conditions and gear mesh stiffness [23].

The difference between the three methods is clearly noticeable for the modal damping. The modal damping increaseswhen moving or comparing the conventional modal analysis to the operational and the order based modal analysis.

Table 8. Estimatednaturalfrequencies and the correspondent modal damping for the three techniques.

\begin{tabular}{|c|c|c|c|c|c|c|c|c|c|c|}
\hline \multirow[b]{2}{*}{ Mode } & \multirow[b]{2}{*}{ Analytical } & \multicolumn{2}{|c|}{ EMA } & \multirow[b]{2}{*}{$\begin{array}{l}\text { Frequency } \\
\text { Error (\%) }\end{array}$} & \multicolumn{2}{|c|}{ OMA } & \multirow[b]{2}{*}{$\begin{array}{l}\text { Frequency } \\
\text { Error (\%) }\end{array}$} & \multicolumn{2}{|c|}{ OBMA } & \multirow[b]{2}{*}{$\begin{array}{l}\text { Frequency } \\
\text { Error (\%) }\end{array}$} \\
\hline & & $\mathbf{f}_{\mathrm{e}}(\mathrm{Hz})$ & $\begin{array}{l}\text { Damping } \\
\text { ratio (\%) }\end{array}$ & & $\begin{array}{c}\mathbf{f}_{\mathbf{e}} \\
(\mathbf{H z})\end{array}$ & $\begin{array}{c}\text { Damping } \\
\text { ratio } \\
(\%)\end{array}$ & & $\mathbf{f}_{\mathrm{e}}(\mathrm{Hz})$ & $\begin{array}{l}\text { Damping } \\
\text { ratio (\%) }\end{array}$ & \\
\hline 1 & 77 & 76 & 0.77 & 1,3 & 74 & 3,34 & $-1,35$ & 72 & 3.2 & 6,49 \\
\hline 2 & 154 & 136 & 1.36 & 11,69 & 129 & 3 & $-2,33$ & 125 & 3.6 & 18,83 \\
\hline 3 & 172 & 169 & 1.61 & 1,74 & - & - & - & 159 & 3.3 & 7,56 \\
\hline 4 & 197 & 195 & 1.49 & 1,02 & - & - & - & 191 & 3.7 & 3,05 \\
\hline 5 & 241 & 251 & 1.06 & $-4,15$ & 248 & 3,11 & $-4,84$ & 250 & 3 & $-3,73$ \\
\hline 6 & 291 & 301 & 1.57 & $-3,44$ & 298 & 3,42 & 0,76 & 294 & 3.41 & $-1,03$ \\
\hline 7 & 320 & 325 & 1.41 & $-1,56$ & 322 & 3,01 & $-0,31$ & 325 & 3.13 & $-1,56$ \\
\hline 8 & 342 & 352 & 1.38 & $-2,92$ & - & - & - & 354 & 3.5 & $-3,51$ \\
\hline 9 & 384 & 378 & 2.00 & 1,56 & - & - & - & 375 & 3.76 & 2,34 \\
\hline 10 & 413 & 406 & 2.54 & 1,69 & 394 & 3,27 & 0,76 & 404 & 2.7 & 2,18 \\
\hline 11 & 436 & 436 & 2.09 & 0 & 432 & 3,51 & $-0,93$ & 441 & 3.29 & $-1,15$ \\
\hline 12 & - & 466 & 2.04 & - & - & - & - & 471 & 2.15 & - \\
\hline 13 & 531 & 526 & 2.16 & 0,94 & 540 & 2,29 & 3,52 & 521 & 3.41 & 1,88 \\
\hline
\end{tabular}

In this case, the comparison between the three techniques is complex because some OMA method modes are missing. That is why, we opted to present another comparison between the EMA and OBMA.

The damping estimates, see (table 9), show a smaller deviation between the two tests than for the natural frequencies. This was which isexpected since the inaccuracy of the frequency estimates are well known to be larger than the damping estimation. TheEMA tests results are, however, in a better agreement with each other than with the OBMA results. This variation is due to the system complex nonlinearity.

Based on these results, we can conclude that the OBMA techniques can be more useful in the extraction of the modal proprieties than the EMA.

Table9shows the difference of the natural frequencies, and modal damping between EMA and OBMA. 
Table 9. Difference between the results of EMA with respect to the OBMA test.

\begin{tabular}{ccc}
\hline Difference of & \multicolumn{2}{c}{ EMA vsOBMA } \\
\cline { 2 - 3 } $\mathbf{1}$ & $f_{\mathrm{n}}[\%]$ & $d_{n}[\%]$ \\
$\mathbf{2}$ & 4 & 2.43 \\
$\mathbf{3}$ & 11 & 2.24 \\
$\mathbf{4}$ & 10 & 1.69 \\
$\mathbf{5}$ & 4 & 2.21 \\
$\mathbf{6}$ & 1 & 1.9 \\
$\mathbf{7}$ & 7 & 1.8 \\
$\mathbf{8}$ & 0 & 1.7 \\
$\mathbf{9}$ & -2 & 2.1 \\
$\mathbf{1 0}$ & 3 & 1.7 \\
$\mathbf{1 1}$ & 2 & 0.16 \\
$\mathbf{1 2}$ & -5 & 1.2 \\
$\mathbf{1 3}$ & -5 & 0.11 \\
& 5 & 1.25 \\
\hline
\end{tabular}

\section{Conclusion:}

Thispaperpresenteda comparison between the Experimental Modal Analysis (EMA) test and the Operational Modal Analysis (OMA) and the Order Based Modal Analysis (OBMA) test achieved on acirculating energy planetary gear. Athree-dimensional lumped parameter model referred to as the test bench was developed. The comparison between the three techniques is achievedin four steps. Firstly, a complete EMA was determined, and the natural frequency, modal damping as well as mode shapes were identified and correlated with the numerical model using the modal assurance criterion and stabilization diagram. In asecond step, the natural frequencies and damping ratios from OMA were extracted experimentally and compared to the those achieved by the numerical model using the cross power spectral density. In a third step, the dynamic behaviour of the test bench was given experimentally and numerically using the order tracking function and stabilisation diagram. The natural frequencies and damping ratios were identified experimentally during the run-up by OBMA. Finally, a comparison between the three methods is carried out.

It was noticed that the comparison is difficult because the OMA technique suffers from missing modes. This phenomenon is due to the fact thatsome modes cannot be excited during the stationary conditions. For this reason, a comparison between the EMA and the OBMA ispresented.

The comparison was studied on [0-540 Hz] frequency bandwidth because run up test was carried out at $1600 \mathrm{rpm}$ input speed. No significant differences were found between the modal parameters obtained by EMA and OBMA. The natural frequencies are deviated by less than $11 \%$ and those of the damping ratios by less than $2.43 \%$. Therefore, the OBMA results in many engineering applications would show higher damping values than the EMA test which is explained by the actual tests boundary conditions of the tests.

In addition, OBMA is aninteresting technique allowing the identification of the modal proprieties because it works under real boundary conditions. Thus, the run-up speed should be increased to define a larger frequency bandwidth.

Three important parameters can be determined in the modal analysis techniques. These are natural frequency, modal damping and modes shapes. As mentioned in the 
introduction, the system in our case is very complex, besides, under a running condition we cannot mount the sensors in the inner parts. Thus, the determination of mode shape as well as the building of the Mac criterion are difficult. Therefore, so only the comparison based on frequency and damping could be achieved.

As a future perspective are planning to develop the inner parts instrument and we will also study the influence of load on the modal parameters for the OBMA.

\section{Acknowledgements}

This paper was financially supported by the Tunisian-Spanish Joint Project No. A1/037038/11. The authors would like also to acknowledge the help provided by the project "Dynamic behavior of gear transmissions in non-stationary conditions", ref. DPI2017-85390, funded by the Spanish Ministry of Science and Technology.

We would like to thank the University of Cantabria cooperation project for the doctoral training to Sfax University students.

\section{References:}

[1] A. Hammami, A. Fernandez, F. Chaari, F. Viadero, M. Haddar, modal analysis of back-to-back planetary gear: experiments and correlation against lumped-parameter model, journal of theoretical and applied mechanics 53, 1, pp. 125-138, Warsaw (2015) DOI: $10.15632 /$ jtam-pl.53.1.125

[2] T.M.Ericson,R.G. Parker, Planetary gear modal vibration experiments and correlation against lumped-parameter and finite element models, Journal of Sound and Vibration, 332, (2013), 2350-237

[3] A.Kahraman, Natural modes of planetary gear trains, Journal of Sound and Vibration, 173, (1994)125-130

[4] L. Zhang, Y.Wang, K.Wu,R. Sheng, Q.Huang, Dynamic modelling and vibration characteristics of a two-stage closed-form planetary gear train, Mechanism and Machine Theory,97, (2016) 12-28

[5]J. Lin, R.G. Parker, Sensitivity of planetary gear natural frequencies and vibration modes to model parameters, J. Sound Vib. 228 (1999) 109-128.

[6]D.R.Kiracofe, R.G. Parker, Structured vibration modes of general compound planetary gear systems, Journal of Vibration and Acoustics,129, (2007), 1-16

[7]Y.Guo, R.G.Parker, Purely rotational model and vibration modes of compound planetarygears, Mechanism and Machine Theory, 45,(2010) 365-377.

[8] S. Chauhan,D. Tcherniak,J. Basurko,O. Salgado,I. Urresti,C.E. Carcangiu,M. Rossetti. Operational modal analysis of operating wind turbines: application to measured data. Rotating Machinery, Structural Health Monitoring, Shock and Vibration, Volume 5,(2011). 65-81.

[9] A. Bajrić, J. Høgsberg, F. Rüdinger, Evaluation of damping estimates by automated Operational Modal Analysis for offshore wind turbine tower vibrations, Renewable Energy, (2017), 0960-1481

[10] S. Gade, R. Schlombs, C. Hundeck, C. Fenselau, "Operational Modal Analysis on a Wind Turbine Gearbox", Proceedings of the IMAC- XXVII, (2009).

[11] E.Di Lorenzo,S.Manzato,J. Houben, F. Vanhollebeke, S. Goris, B. Peeters. Wind Turbine Gearbox Dynamic Characterization Using Operational Modal Analysis. Volume 7 (2014). (pp. 41-52). Springer, Cham.

[12]E. Di Lorenzo, S. Manzato, F. Vanhollebeke, S. Goris, B. Peeters, W. Desmet, F. Marulo. Dynamic characterization of wind turbine gearboxes using Order-Based Modal Analysis. international conference on noise and vibration engineering (isma2014) and international conference on uncertainty in structural dynamics (USD2014)(2014). pp. 4349-4362. 
[13] R.B. Randall, M.D. Coats, W.A. Smith, Repressing the effects of variable speed harmonic orders in operational modal analysis, Mechanical Systems and Signal Processing, (2016), pp.3-15,

[14]A. Hammami, A. Fernandez, F. Chaari, F. Viadero, M. Haddar, Dynamic behaviour of backto-back planetary gear in run up and run down transient regimes, Journal of Mechanics, (2015), 481-491.

[15] K. Janssens, Z. Kollar, B. Peeters, S. Pauwels, H. Van der Auweraer. Order-based resonance identification using operational PolyMAX. Proc. of 24th IMAC Conference on structural dynamics, St. Louis, US (Vol. 30) 2006.

[16]PEETERS, Bart, VAN DER AUWERAER, Herman, GUILLAUME, Patrick, et al. The PolyMAX frequency-domain method: a new standard for modal parameter estimation? Shock and Vibration, 2004, vol. 11, no 3-4, p. 395-409.

[17]E. Di Lorenzo, S. Manzato, F. Vanhollebeke, S. Goris, B. Peeters, W. Desmet, F. Marulo. Dynamic characterization of wind turbine gearboxes using Order-Based Modal Analysis. international conference on noise and vibration engineering (isma2014) and international conference on uncertainty in structural dynamics (USD2014)(2014). pp. 4349-4362.

[18] E. Orlowitz, A. Brandt, Comparison of experimental and operational modal analysis on a laboratory test plate, Measurement, (2017), 121-130.

[19] A. Hammami, A. Fernandez. Chaari. Iglesias, F. Viadero, M. Haddar. Effects ofvariable loading conditions on the dynamic behavior of planetary gear withpower recirculation. Measurement (2016); 94:306-15.

[20] V.B. Corey, Measuring angular accelerations with linear accelerometers, Control Engineering (1962) 79-80.

[21] A. Kahraman, G.W. Blankenship, Experiments on nonlinear dynamic behaviour of an oscillator with clearance and periodically time-varying parameters, Journal of Applied Mechanics 64 (1997)217-226.

[22] M. Karray,N. Feki, M.T. Khabou, F. Chaari, M. Haddar, Modal analysis of gearbox transmission system in Bucket wheel excavator, Journal of theoretical and applied mechanics 55, 1, pp. 253-264, Warsaw (2017) DOI: 10.15632/jtam-pl.55.1.253

[23] A. Mbarek, A. Hammami, A. Fernandez Del Rincon, F. Chaari, F. Viadero Rueda, M. Haddar, Effect of load and meshing stiffness variation on modal properties of planetary gear. Applied Acoustics (2017) doi.org/10.1016/j.apacoust.2017.08.010 .

[24] Dhatt, G., Touzot, G. and Lefrançois, E. (2005) Méthode des Éléments Finis - Une Présentation, Hermès Science Publications, Paris, France

[25] J. Lin, R.G. Parker, Analytical characterization of the unique properties of planetary gearfree vibration, Journal of Vibration and Acoustics, 121,(1999), 316-321

[26] M. Pastor, M. Binda, T. Harčarik, Modal Assurance Criterion, Procedia Engineering, Volume 48, 2012, Pages 543-548, ISSN 1877-7058,

[27] M. Inalpolat, A. Kahraman. A theoretical and experimental investigation of modulation sidebands of planetary gear sets. Journal of Sound and Vibration 323:(2009) 677-696

[28] G. Arfken, "Discrete Orthogonality--Discrete Fourier Transform.". Mathematical Methods for Physicists, 3rd ed. Orlando, FL: Academic Press, (1985) 787-792,

[29] E. Orlowitz, A. Brandt, Influence of correlation estimation methods on dampingestimates, in: Proceedings of 5th International Operational Modal AnalysisConference, Guimaraes, Portugal, 2013.

[30] FYFE, K. R. et MUNCK, E. D. S. Analysis of computed order tracking. Mechanical Systems and Signal Processing, 1997, vol. 11, no 2, p. 187-205. 
[31]M.T. Khabou, N. Bouchaala, F. Chaari, T. Fakhfakh, M. Haddar, Study of a spur gear dynamic behavior in transient regime, Mechanical Systems and Signal Processing 25 (2011) 3089-3101

[32]F. Viadero, A. Fernández, M. Iglesias, A. de-Juan, E. Liaño, M.A. Serna, Nonstationary dynamic analysis of a wind turbine power drivetrain: Offshore considerations, Applied Acoustics 77 (2014) 204-211 